\title{
Natural Convection Heat Transfer of Hydrophilic Particle Suspension: Implications on Nuclear Waste Remediation
}

\author{
Izumi Hagiwara $^{1}$, A. Tokuhiro ${ }^{2}$, P. G. Oduor ${ }^{3}{ }^{*}{ }^{*}$
}

\begin{abstract}
Natural convection of gel suspension has the potential to be applied to particulate recovery systems, such as in the dynamic filtering of radioactive waste particles. In this study, experiments were conducted to assess natural convection of gradually settling gelatin particle suspension in a rectangular cell, relative to single-phase natural convection with bulk temperature stratification, and to derive empirically a transfer relationship. The rectangular cell used had one vertical wall maintained at a lower temperature and the opposite wall at a relative thermal high. Two different sizes of gelatin particles were used. Local heat transfer coefficients were calculated from wall and bulk temperature measurements. Velocity field characteristics were determined using an Ultrasound Velocity Profiler (UVP). Heat transfer results showed both enhancement and de-enhancement in Nusselt number depending on temperature difference and particle size. The four necessary conditions to induce heat transfer enhancement in this setup and effect of sediment layer on heat transfer are discussed. The ultimate goal of this study was to examine a method of a dynamic filtering system that separated particles from wastewater using thermally-induced volumetric expansion and/or contraction of similarly sized functional gels that could be applied conceptually to nuclear waste remediation. For single-phase, the effect
\end{abstract}

\footnotetext{
${ }^{1}$ Formerly at University of Missouri-Rolla (Missouri University of Science and Technology), Nuclear Engineering Department, Missouri University of Science and Technology, 222 Fulton Hall, 301 W. 14th St., Rolla, MO 65409-0170 (h19_izumi@ hotmail.com)

${ }^{2}$ Akira Tokuhiro, Nuclear Engineering Dept., Idaho Falls Center for Higher Education, 1776 Science Center Drive, Ste 306, Idaho Falls, Idaho 83402 (tokuhiro@uidaho.edu)

${ }^{3}$ Dept. of Geosciences, North Dakota State University, Fargo, ND 58108 (Peter.Oduor@ndsu.edu)

*Corresponding Author
} 
of thermal stratification on natural convection heat transfer can be accounted for by using a stratification factor, $S$, and for dual-phase, a stratified Nusselt number given the notation- $s N u$. The reduction in the spread of data point relative to plotting $N u_{\mathrm{y}}$ against $R a_{\mathrm{y}}$, indicates that plotting the stratified local Nusselt number, $s N u_{\mathrm{y}}$, versus the local Rayleigh number, $R a_{\mathrm{y}}$, is appropriate. More importantly the analytical dependence to the Rayleigh number $\left(R a_{\mathrm{y}}{ }^{1 / 4}\right.$ for laminar and $R a_{\mathrm{y}}{ }^{1 / 3}$ for turbulent) was preserved and within variations seen in the literature.

Keywords: Hydrophilic particle; velocity profile; single-phase flow; two-phase flow. 


\section{Introduction}

Decontamination of effluents, such as wastewater that contains radioactive isotopes, heavy metals, or hazardous solid particulates, is a subject of great interest [1-4]. This interest has culminated in rapid growth of waste remediation and minimization directives and procedures. Typically, radioactive waste storage tanks contain hazardous and radioactive matter resulting from the production of nuclear materials, fuel, cladding etc. As the tanks age, the possibility of waste escaping to the environment increases. To minimize the risk of waste migration and exposure to workers, the public, and the environment, the waste must be retrieved and the tanks sealed. A primary remediation procedure for this kind of contamination is to separate metal particulates from the liquid waste. Since the thermal properties of each metallic constituent are different, a natural convection cell can be used to enhance separation. These mobile suspended particulates can therefore adhere to suspended materials like gels. Separating radioactive particles from liquid waste plays an important role in radioactive waste remediation since it reduces the volume of waste to be treated as radioactive. Moreover, if the most radioactive and long-lived isotopes could be greatly separated from a waste stream then the problems of storage and containments would be substantially simplified.

A dynamic filtering system can be used to recover particulate solids, such as radioactive particles, from a mixed waste stream using a class of gels, which swell and shrink in response to an applied temperature change. Several gels and gel-like materials are known to undergo an abrupt change, or phase transition, between collapsed and swollen states depending on their composition. For example, poly(acrylamide) swells with increasing temperature, while poly $(N-$ alkyl substituted acrylamide) swells with decreasing temperature. These changes can occur in response to minute changes in their physical environment, such as, temperature, solvent 
24 composition, $\mathrm{pH}$, ionic strength, light and electric field [5-12]. These functional materials have

25 been studied for many purposes, including, controlled drug delivery, filtration at molecular level, 26 extraction solvents for proteins, and concentration of dilute suspensions [13-19]. Some of these

27 materials can be obtained from polymers that exhibit lower critical suspension temperatures

28 (LCST). Examples of these include and are not limited to polyethylene oxide, hydroxypropyl

29 cellulose, polyvinyl alcohol and derivatives of poly acrylamides [19].

Natural convection with particles is different from that of single-phase natural convection and is regarded as two-phase flow. Two-phase flows consist of liquid-liquid, liquid-gas, liquid-

32 solid particles, or gas-solid particles. In liquid-solid particles suspension, particles will tend to 33 settle out of suspension and sediment in most cases. The bottlenecks experienced in any 34 analyses arise due to this settling further contributing to a quantitative complication. 35 Sedimentation of particles and natural convection can occur simultaneously. Sedimentation and suspension flows are of importance, especially in the field of solid-liquid separations in the 37 chemical, mining, pulp and paper, wastewater, food, pharmaceutical, ceramic and other industries. Also, the sedimentation of particles from a convecting fluid is a process of much interest to engineers, fluid dynamicists, geologists and metallurgists. For example, the process 40 plays a fundamental role in controlling the settling behavior of phenocrysts in magma chambers, 41 crystals and impurities in metallic castings and carbon microparticles in combustion chambers 42 [20]. Although intensively studied for many years, an understanding of sedimentation and suspension flows is still far from complete. 45 including properties of suspensions (rheology, particle size and shape, particle-particle interaction, surface characteristics, yield stress, concentration, viscosity), individual particles 
47 (orientation and surfactants), and sediments (permeability, porosity and compressibility).

48 Studies on two-phase liquid-solid flows and suspensions in relation to settling and focused on

49 hydrodynamics have been reported [21-33]. Koyaguchi et al. [20] investigated sedimentation of

50 silicon carbide particles from a convective fluid experimentally by using a tank heated from

51 below. They showed that convective motion due to heating from below can be affected by the

52 presence of particles and is controlled by the bulk density of a particulate suspension. Stommel

53 [21] investigated trajectories of the particles sinking slowly through convection cell, which is

54 heated from below, analytically. He classified the trajectories of particles in terms of the

55 quantity, which is the ratio of the settling velocity to the maximum upward water velocity. Most

56 of these studies have primarily dealt with the convective motion due to heating from below.

For liquid-solid particle flow it is also recognized that suspensions of solid particles have

58 great potential to enhance the heat transfer. For two-phase gas-solid particle flow, Murray [34]

59 investigated the mechanisms associated with the enhancement of heat transfer over the front of a

60 tube in a gas-particle cross flow. Plass and Molerus [35] investigated wall-to-suspension heat

61 transfer of solid-liquid pipe flow. In order to clarify how particle in suspension affect the

62 structure of flow, Zisselmar and Molerus [36] investigated solid-liquid pipe flow with regard to

63 turbulence modification using laser-Doppler anemometry. They concluded that the intensity of

64 turbulence is significantly affected by the size of the solid particles. Moreover, as the size of the

65 particles increased, the turbulence intensity was dampened depending on solids concentration as

66 well as on distance from the wall. Mechanisms of heat flow in such suspensions have also been

67 studied using nano-sized particles (see [37]). These nano-sized particles are also referred to as

68 nanofluids. Khanafer et al. [38] investigated heat transfer enhancement in an enclosure utilizing

69 these nanofluids. They concluded that the suspended nano-sized particles substantially increased 
70 the heat transfer rate. Also, the nanofluid heat transfer rate increased with an increase in the

71 nano-sized particle volume fraction. In addition, they found that the presence of nano-sized

72 particles in the fluid altered the structure of the fluid flow. For micron-sized particle

73 suspensions, Hattori et al. [39] investigated transient natural convection of glass beads

74 suspension in a rectangular cell heated and cooled along opposing vertical walls. However their

75 aim was to observe transient changes of natural convection in particle suspension, and as such

76 steady-state natural convection was not investigated.

Hoffman et al. [14, 15, 40] showed that temperature sensitive gels could be used to

78 selectively or non-selectively remove undesirable toxins, to assay for specific substances, and to

79 recover selected products of a biochemical process. This process may also be applied in a non-

80 biochemical situation. The basis of the design proposed in this study is formulated from

81 Hoffman's et al., [14, 15, 40] work. In this scenario, first, a dried (collapsed) temperature

82 sensitive gel is immersed in mixed wastewater, which contains solid particles. The system is

83 heated above lower critical suspension temperature (LCST) so that the gel swells. Since gel is

84 hydrophilic, it absorbs water and may absorb or encapsulate small solid particles. The system is

85 then cooled below LCST so that the gel collapses. In this state, it releases only water, and the

86 solid particles are captured or adhere to the gel. The main focus of this study was to investigate

87 natural convection heat transfer of gelatin suspension in comparison to deionized water. The

88 specific objectives were: (1) to quantify natural convection heat transfer of hydrophilic particle

89 suspension with particle size and particle loading as parameters; (2) to measure temperature

90 profiles in fluid near a heated wall for both single-phase and two-phase natural convection; and

91 (3) to obtain the velocity profiles of natural convection with and without micron-sized,

92 hydrophilic particles of various sizes and particle loading by Ultrasound Velocity Profile (UVP). 
93 Additionally, the problem of bulk temperature stratification in natural convection of single-phase

94 was also investigated.

95

96 Methods

97 Rationale

Since a two-phase flow was the backbone of this study, a selection criterion of the solid phase was established. The solid phase used had to be a readily available low cost material. It also had to be a water-absorbing (hydrophilic) particle, which swells in water; and that it should

101 have the capability of transporting thermal energy from hot to cold in a thermal convection cell.

102 Its diameter was expected to be around 50 to $200 \mu \mathrm{m}$, a size ideal for velocity measurement 103 using acoustic velocity measurement methods. Also the particle needed to have a density nearly 104 equal to that of water so that some particles may follow the convective flow and some sediment 105 out as they become heavier. Its solubility in water over an appropriate temperature range (lower 106 than thermally induced evaporation of fluid used) also was to be extremely low. After testing 107 several kinds of particles like tapioca particles, silica gels, gelatin (Knox Gelatine, unflavored) 108 was chosen.

Gelatin is a pure protein obtained from animal raw materials containing collagen. It is usually found in granular powder form and its diameter is small enough to meet the selection criterion. Also, it is relatively insoluble in cold water; however dry gelatin swells or hydrates 112 when stirred into cold water. Its solubility increases closer to boiling point of water. The 113 measured bulk density of dried gelatin particle was $680 \mathrm{~kg} / \mathrm{m}^{3}$, where the bulk density indicates 114 the ratio of mass of gelatin particles to the bulk volume of it. The density of the gelatin particles 115 in water was determined using Archimedes' principle by measuring the volume variation when a 
116 weighted amount of particles was introduced into 20 milliliters of distilled water in a graduated

117 cylinder. The gelatin particle density in water was $1390 \mathrm{~kg} / \mathrm{m}^{3}$. The bulk density is lower than

118 that of true density because the bulk volume includes pore space remaining in the material. The

119 true density of a pure substance is calculated from its components' densities considering

120 conservation of mass and volume. The true density of gelatin is about $1270 \mathrm{~kg} / \mathrm{m}^{3}[41]$.

121

122 Medium

Deionized water was used as a working fluid in these experiments and in the circulator

124 baths. About 20 liters of deionized water was needed to fill the experimental cell for a run. In

125 order to prevent air bubbles from attaching to the inner surface of the Plexiglas walls, the water

126 was boiled to allow dissolved gas to escape and then cooled to room temperature in a covered

127 container. The gelatin particles were screen fractionated using United States Standard Testing

128 Sieves (Fisher Scientific Company) and Central Scientific Company’s Sieve Shaker (Catalog No.

129 18480). The sieves were placed on the sieve shaker in descending mesh size starting at the top

130 of a stack of four. A small quantity of particles (about $100 \mathrm{~g}$ ) was placed in the top sieve and the

131 shaker was operated for 10 to 15 minutes. At the end of the shaking period, the sieves were

132 separated and their contents placed in individually labeled plastic bags. The screening was

133 continued until a sufficient quantity of particles was obtained for the experiment. Particles were

134 divided into four groups in concomitance with sieve sizes. The group, which had median

135 particle diameter of $138 \mu \mathrm{m}$, was not used because of its large size even though it met the

136 selection criterion. The group, which had a median particle diameter of $60 \mu \mathrm{m}$, was combined

137 with the group whose median particle diameter was less than $45 \mu \mathrm{m}$, since the individual sized

138 amounts were too little for effective analysis. Thus, two different particle sizes were used in this 
139

140

141

142

143

144

145

146

147

148

149

150

151

152

153

154

155

156

157

158

159

study. One consisted of particles that went through the No. 200 sieve, particle diameter, $d_{\mathrm{p}}=d_{1}$, and the other consists of particles that spanned No. 200 and No. 325, particle diameter, $d_{\mathrm{p}}=d_{2}$.

The gelatin particle sizes of both wet and dry state were then determined using a SMZ800 Nikon microscope fitted with a digital camera. The determination of a particle size distribution was carried out by measuring the size of a number of particles. Since the gelatin particles have irregular shapes, it was hard to accurately quantify the true diameter. To get over this problem, Martin's diameter method, one that has been widely used was adopted. Martin's diameter was used to obtain a representative size of the individual particles. Martin's diameter is defined as the length of a line, parallel to the fixed direction of scan, which divides the particle into two equal areas (e.g. $[42-44])$. The use of this diameter is based on the proposition that although the smallest diameter of some particles and the largest dimension of others may be determined, the resulting errors tend to be compensating if sufficient particles are measured. Concerning this proposition, at least 100 particles were taken as a sample size. The diameter values obtained for the gelatin particles used for this study were determined. The number of particles in each size interval, $\Delta d$, which would be large enough to contain many particles, yet small enough to obtain sufficient detail, was determined. Gelatin particle sizes, $d_{\mathrm{p}}=d_{1}$, in wet state and $d_{\mathrm{p}}=d_{2}$ in dry state were determined. The number-average particle diameter in the particle size distribution was obtained from $\bar{d}=\sum n_{i} d_{i} / \sum n_{i}=\sum n_{i} d_{i} / N=\sum_{i} f_{i} d_{i}$ with normalized distribution such that $\sum_{i=1}^{N} f_{i}=1 . f_{i}$. is ordinate corresponding to each size interval as represented by a frequency value. The variance of the diameter values was determined from $\sigma^{2}=\sum n_{i}\left(d_{i}-\bar{d}\right)^{2} / \sum n_{i}=\sum_{i} f_{i}\left(d_{i}-\bar{d}\right)^{2}$ 
Tracer particles were used to gauge the velocity profile of particles in the convection cell.

161 The tracer particles used in this study were nylon seeding particles (Expancel microspheres, 091

162 DU 80, Akzo Nobel). Expancel microspheres are off-white (easy to track), spherically formed

163 particles with a thermoplastic shell encapsulating air. The particle size is about 18 to $24 \mu \mathrm{m}$ and

164 the measured density of dried particle was $503.6 \pm 4.3 \mathrm{~kg} / \mathrm{m}^{3}$. Expancel microspheres as a tracer

165 provide an ideal particle for two-phase flow velocity measurements. These particles have been 166 used in research dealing with Ultrasound Velocity Profile (UVP) (e.g. [45]). The next part of the 167 experiment was to obtain the suspensions. Particles and fluid were mixed just prior to each run. 168 In some cases, the suspension was kept in a carefully sealed sterile container for reuse. The 169 volume of suspension required for a run added to a fraction of the 20 liters of deionized water 170 used. The concentration of tracer particles was based mainly on experience and was chosen to 171 optimize the velocity measurement results.

Test apparatus

The experiments were carried out in an experimental cell of dimensions $100 \mathrm{~cm}$ high by $17550.05 \mathrm{~cm}$ wide and $2.54 \mathrm{~cm}$ depth. The experimental cell itself was made of two Plexiglas sheets $176106.7 \mathrm{~cm}$ high, $61 \mathrm{~cm}$ wide, and $0.943 \mathrm{~cm}$ thickness. Ideally the depth of the natural convection 177 cell is supposed to be large enough to avoid interference between the sidewalls and the central 178 region. This was not the case for this study owing to unavoidable limitations on the number of 179 support apparatus that would have to be used with a larger cell. This scaled down version still 180 offered adequate results. The aluminum and PVC square channels were sandwiched between the 181 two Plexiglas sheets on both sides. The aluminum channel was $2.54 \mathrm{~cm}$ square cross-sectional 182 area and had a wall thickness of $3.18 \mathrm{~mm}$ whereas the PVC channel was $2.54 \mathrm{~cm}$ square and 2.0 
$183 \mathrm{~mm}$ thick. Since aluminum has a higher thermal conductivity, it was placed in the inner side of 184 the cell for the hot and cold ends of the experimental cell. On the other hand, the low thermal 185 conductivity PVC channels were placed at the outer exposed side to prevent heat loss to the 186 ambient. Plexiglas sheets, aluminum and PVC channels were glued with clear, waterproof 187 adhesive (UV6800, Eclectic Products, Inc.). The bottom of the cell was also closed with a PVC 188 channel. The aluminum tubes, which were placed on both ends of the cell were heated and 189 cooled respectively by water running through them. The temperature of both hot and cold walls 190 of the cell was controlled by two constant temperature (refrigerator-heater) LAUDA RM6 191 Brinkman Instruments circulating baths. Each circulating bath had a 6 liter fluid capacity and $19215^{\circ} \mathrm{C}$ to $120^{\circ} \mathrm{C}$ temperature range with an accuracy limit of $\pm 0.02^{\circ} \mathrm{C}$. First, the water from 193 circulating bath flowed downward through the aluminum channels located at the sides. Since the 194 aluminum and PVC channels were connected at the bottom, water flowed from the aluminum 195 channel into the PVC channel. The next cycle of flow was through the PVC channel to 196 discharge water in the circulating bath. To further minimize heat loss the Plexiglas enclosure 197 was insulated with polystyrene. The PVC provided insulation for the sides and bottom. A 198 schematic representation the setup is shown in Figure 1.

Fig. 1 shows an illustration of how deionized water flows through the circulator baths.

200 Ten Chromel-Alumel thermocouples (36 AWG) were attached at length spacing of $10.16 \mathrm{~cm}$ 201 from each other along the entire wall surface and covered using a thin ( $0.05 \mathrm{~mm}$ thick) aluminum 202 tape. In order to prevent water from getting into the gap between the thermocouple tip and 203 aluminum tape, the tape was coated with a waterproof adhesive. The actual hot wall temperature 204 was thus the temperature of the aluminum sheet surface. The thermocouples attached to the 205 aluminum sheet recorded this value. To correct for any heat losses, to determine an accurate 
value for temperature of the wall, both outer and inner surface temperatures of the aluminum

207 channel were measured. The temperature within the test cell was measured by a traversing 208 thermocouple probe, which consisted of ten Chromel-Alumel 20 AWG thermocouples within a 209 plastic tube of $1.27 \mathrm{~cm}$ in diameter. These thermocouples were calibrated using a thermocouple 210 calibrator (CL-307, Omega Engineering, INC.). The temperature at ice point and boiling point 211 were used as checks. The temperature of the thermocouple and reference thermocouple 212 calibrator accuracy limit was $\pm 2.3^{\circ} \mathrm{C}$. Errors resulting from the measurement techniques were 213 estimated by taking the derivatives of each of the desired parameters with respect to each of the 214 measured quantities. It was assumed that the random error of the temperature differences 215 measured with the type $\mathrm{K}$ thermocouples was $0.5^{\circ} \mathrm{C}$. The thermocouples were positioned at: (i) $21694.44 \mathrm{~cm}$, (ii) $84.28 \mathrm{~cm}$, (iii) $74.12 \mathrm{~cm}$, (iv) $63.96 \mathrm{~cm}$ (v) $53.80 \mathrm{~cm}$, (vi) $43.64 \mathrm{~cm}$, (vii) 33.48 $217 \mathrm{~cm}$, (viii) $23.32 \mathrm{~cm}$, (ix) $13.16 \mathrm{~cm}$, and (x) $3.00 \mathrm{~cm}$ from the bottom. A second experimental cell 218 (cell B) was used to measure the temperature difference between the inside and outside of the 219 aluminum tube. Thermocouples were attached to walls in the same way as in the first cell. In 220 the second cell, 32 AGW Chromel-Alumel thermocouples were used for temperature 221 measurements at the hot end wall, and 20 AGW Chromel-Alumel thermocouples were used for 222 the cold end wall. Also on the hot side, five 32 AGW Chromel-Alumel thermocouples were 223 attached to the inside of the aluminum tube on the hot side (Positions (i) $94.44 \mathrm{~cm}$, (ii) $84.28 \mathrm{~cm}$, 224 (vi) $43.64 \mathrm{~cm}$, (viii) $23.32 \mathrm{~cm}$ and (x) $3.00 \mathrm{~cm}$ ). A $0.05 \mathrm{~mm}$ thick aluminum sheet also covered 225 each thermocouple in the second cell.

226 The hot wall temperature $\left(T_{\text {hot }}\right)$ was obtained from calculating the temperature difference 227 between inside $\left(T_{\text {inside }}\right)$ and surface $\left(T_{\text {surface}}\right)$ of the aluminum tube using Fourier's law of heat 228 conduction. Figure 2 shows a cross section diagram of the hot wall, which consisted of an 
229 aluminum channel wall of thickness $L_{1}=3.18 \mathrm{~mm}$ and an aluminum tape of thickness $L_{2}=0.05$

$230 \mathrm{~mm}$. From Fourier's law of heat conduction, if there exists a homogeneous phase, then the local

231 heat flux is proportional to the negative of the local temperature gradient can be obtained from

$232 q_{\mathrm{x}}^{\prime \prime}=-k(d T / d x)$ where $q_{\mathrm{x}}^{\prime \prime}$ is the heat flux in $\mathrm{W} / \mathrm{m}^{2}$, or heat transfer rate in the $x$ direction per unit

233 area perpendicular to the direction of transfer. $T$ is the local temperature in ${ }^{\circ} \mathrm{C}$ and $x$ is the

234 coordinate in the heat flow direction in length units like meters. $k$ is the thermal conductivity of

235 the substance in $\mathrm{W} / \mathrm{m} \mathrm{K}$ and is a characteristic of the wall material. The minus sign is a

236 consequence of the fact that heat is transferred in the direction of decreasing temperature.

The temperature gradient within the aluminum channel wall under the steady-state

238 conditions where the temperature distribution is linear was calculated from

$239 d T / d x=\left(T_{\text {inside }}-T_{\text {surface }}\right) / L_{1}$, whereas for the aluminum tape, the expression used was

$240 d T / d x=\left(T_{\text {surface }}-T_{\text {wall }}\right) / L_{2}$. The heat flux was calculated from the relation

$241 q_{\mathrm{x}}^{\prime \prime}=-\left(k / L_{1}\right)\left(T_{\text {inside }}-T_{\text {surface }}\right)=-\left(k / L_{2}\right)\left(T_{\text {surface }}-T_{\text {wall }}\right)$. From the experiment, the value of thermal

242 conductivity for aluminum was obtained from standard tables as $204 \mathrm{~W} / \mathrm{m} \mathrm{K}$. Thus, the

243 aluminum surface temperature $\left(T_{\text {wall }}\right)$ can be calculated using the aluminum channel inside wall

244 temperature, $T_{\text {inside, }}$ and the aluminum channel surface temperature, $T_{\text {surface }}$ from the equation

$245 T_{\text {wall }}=T_{\text {surface }}-\left(L_{2} / L_{1}\right)\left(T_{\text {inside }}-T_{\text {surface }}\right)=T_{\text {surface }}-0.0157\left(T_{\text {inside }}-T_{\text {surface }}\right) . \quad$ The $\quad$ maximum

246 temperature difference between the aluminum channel inside and surface $\left(T_{\text {inside }}-T_{\text {surface }}\right)$ was 1.93

$247{ }^{\circ} \mathrm{C}$ and corresponding temperature difference between the aluminum channel surface and the real

248 wall temperature $\left(T_{\text {wall }}-T_{\text {surface }}\right)$ was $0.03{ }^{\circ} \mathrm{C}$. Therefore since the difference was relatively small,

249 the aluminum surface temperature was used as the sheet temperature for both hot and cold ends. 
Velocity of the fluid adjacent to the hot wall of the natural convection cell was obtained

253 by means of a Met-Flow Ultrasound Doppler Velocimetry (UDV). This works by utilizing the

254 pulsed echo technique of ultrasound to detect the Doppler shift of ultrasound waves reflected 255 from moving particles suspended in a fluid (e.g. [46, 47]). Spatial resolution was possible by 256 measuring simultaneously the time after emission of the ultrasound pulse. Hence, a full velocity 257 profile along the ultrasound beam was instantaneously obtained by the UDV in space and time. 258 Three ultrasonic $4 \mathrm{MHz}$ UVP transducers each with an active diameter of $5 \mathrm{~mm}$ (diameter of 259 active transmitting area) were fixed vertically on top of the convective cell and used to transmit a short emission of ultrasound along a measuring line into the flow field of interest. When a pulse

261 hit a small solid phase particle suspended within the flow, part of the energy was scattered from 262 the particles and a fraction reflected back. The transducer then switches over to a receiving 263 mode to pick-up the reflected echo. particles pass through the measurement volume. The velocity of the suspended particles within 266 the convective cell, $u_{\mathrm{p}}$, was obtained from, $u_{\mathrm{p}}=\left(c f_{d} / 2 f_{0}\right)$, where $c$ was the velocity of 267 ultrasound in the two-phase flow being investigated, $f_{\mathrm{d}}$ the Doppler frequency shift, and $f_{0}$, the 268 ultrasound frequency. In this manner, the velocity of the solid phase gelatin particles could be 269 calculated at each point. UVP uses a beam of ultrasound that is emitted from a transducer to 270 obtain simultaneous velocity measurements along a profile. In order to achieve an accurate 271 velocity profile, the return signal detected from the shift in frequency in the convective cell was 272 gated at certain times, thereby allowing measurements of velocity at up to 128 points along the 273 axis of the ultrasound beam. The distance to the location of each solid phase particle, $X$, was 
274 calculated from, $X=1 / 2(c t)$, where $t$ is the time lapse between the emission and reception of 275 ultrasound pulses.

276

277

278

279

280

281

282

283

284

285

286 287 setting of $5 \mathrm{~mm}$ and a divergence of the ultrasound beam of $2.2^{\circ}$.

The vertical velocity components were obtained in the vicinity of the hot wall. Three 4 MHz transducers, which haseach with a diameter of $8 \mathrm{~mm}$ (active diameter is of $5 \mathrm{~mm}$ ) were fixed vertically on top of the cell (Fig. 3). The distance between the transducers was $12.7 \mathrm{~mm}$. The probes were installed $103 \mathrm{~cm}$ above the bottom of the cell and were moved in a traverse direction towards the center of the cell at 1 to $4 \mathrm{~mm}$ intervals. The typical UVP online software window displays measured velocity as a function of spatial distance from the ultrasound transducer. The measurement of a velocity profile with UVP required a parametric configuration to calibrate the input values. The parameters used for configuration are: an ultrasound frequency of $4 \mathrm{MHz}$, a pulse repetition rate of $987 \mathrm{~Hz}$, a measurable depth of $750 \mathrm{~mm}$, a velocity resuspension setting of $0.74 \mathrm{~mm} / \mathrm{s}$, a time resuspension (single profile) value of $32.4 \mathrm{~ms}$, velocity of sound in water (at $20^{\circ} \mathrm{C}$ ) standardized at $1,480 \mathrm{~m} / \mathrm{s}$, a minimum ultrasound beam diameter experiments were conducted by using cell A. The suspensions were prepared using deionized

294 water and gelatin particles of average particle sizes $d_{1}=134 \mu \mathrm{m}$ and $d_{2}=230 \mu \mathrm{m}$. The particle 295 loading $\phi_{\mathrm{p}}$ in weight percent, were $\phi_{1}=0.026 \mathrm{wt} \%, \phi_{2}=0.104 \mathrm{wt} \%, \phi_{3}=0.26 \mathrm{wt} \%$, and $\phi_{4}=$ 
$0.518 \mathrm{wt} \%$. The temperature difference between hot and cold wall was set according to the temperature difference of circulator water bath on both sides $\left(\Delta T_{\mathrm{Bath}}=T_{\mathrm{HB}}-T_{\mathrm{CB}}\right) . \quad T_{\mathrm{HB}}$ and $T_{\mathrm{CB}}$ were set up temperatures for hot water bath and cold water bath, respectively. $\Delta T_{\text {Bath }}$ was set at $5^{\circ} \mathrm{C}, 10^{\circ} \mathrm{C}, 15^{\circ} \mathrm{C}$, and $20^{\circ} \mathrm{C}$ for single-phase runs and $10^{\circ} \mathrm{C}$ and $20^{\circ} \mathrm{C}$ for the two-phase runs. The corresponding temperature difference between hot and cold wall ( $\Delta T=\bar{T}_{\text {hot }}-\bar{T}_{\text {cold }}$ ) varied according to the surrounding environment, that is, the room temperature also referred to as the ambient temperature in this study. All physical properties of working fluid were evaluated at the film temperature, $T_{\text {film }}=\left(\bar{T}_{\text {hot }}+\bar{T}_{\text {cold }}\right) / 2$, where $\bar{T}_{\text {hot }}$ is the mean temperature of the hot wall surface and $\bar{T}_{\text {cold }}$ is the mean temperature of the cold wall surface. $\bar{T}_{\text {bulk }}$ is the mean bulk temperature within the cell. The Rayleigh number, $R a$, is the dimensionless parameter and $R a_{\mathrm{H}}$ is the Rayleigh number based on height of the cell, $H=100 \mathrm{~cm}$, and temperature difference between hot and cold wall, $\Delta T=\bar{T}_{\text {hot }}-\bar{T}_{\text {cold }}$. Other thermophysical properties for water were found from standard tables (for values see [48]).

In a typical run the experimental cell was first cleaned. Then the cold and hot baths were filled with cooled and heated water. Care was taken to check for any water leak. The cell was then filled with deionized and deaired water at room temperature. The circulating water baths for both heating and cooling were then turned on. During the entire run the water bath temperatures was measured every thirty minutes. The thermocouple probe was inserted into the cell and placed in the center of the cell. The centerline temperatures of the cell and hot wall temperatures were measured every thirty minutes until steady-state was attained. Steady-state was achieved when there were no fluctuations greater than $0.2^{\circ} \mathrm{C}$ in the thermocouple probe readings taken at the center of the cell over a timer interval of thirty minutes. The cold wall temperatures were monitored and recorded every fifteen minutes using a Data Acquisition 
319 System (Personal Daq, IOtech). For runs with gelatin suspension, gelatin particles were mixed

320 into the water and thoroughly dispersed by using an electrical mixer before placing the mixture

321 in the cell. The sediment layer depth was measured at the several locations using a graduated

322 vertical scale. The steady-state was attained after about six hours from start-up. The

323 thermocouple probe was moved along the top length of the cell, and temperature measured with

324 a 54II FLUKE thermocouple thermometer; to obtain temperature profiles.

325 The acquisition of all temperature data took about twelve hours for each run. Velocity

326 measurements were taken after temperature measurements for several runs. Generally,

327 ultrasound reflecting tracer particles (Expancel 091DU80, diameter is about $20 \mu \mathrm{m}$ ) were added

328 after temperature measurement was taken. The tracer particles were thoroughly mixed before

329 adding them into the test cell. The entire cell was stirred using a long wooden stick, the effect of

330 the tracer particles on temperature determination was assumed negligible. Velocity

331 measurements were taken after three to four hours. The ultrasound transducers were moved

332 along the top of the cell to obtain several readings at different points.

334 Results and discussion

Figs 4 (A) and (B) show the bulk temperatures measured along a vertical line placed 336 midway between the hot and the cold wall. The temperatures are plotted in a dimensionless way 337 as ratio of the bulk temperature minus the cold wall temperature to the hot plate temperature 338 minus the cold wall temperature. Fig. 4 (A) shows the temperature profiles for single-phase 339 natural convection. It can be observed that the bulk temperatures of the experimental cell are not 340 constant but vary approximately in a linear fashion. The bulk temperature increases with height 341 from the bottom of the cell increases, such that the warmer layers stabilize for the upper position 
342 and there is a gradual cooling towards the bottom. This is called thermal stratification of the

343 fluid. The stratification parameter, $S$, indicates the effect of the thermal stratification and defined

344 as $S=\left(T_{\text {top }}-T_{\text {bottom }}\right) /\left(T_{\text {hot,y }}-T_{\text {bulk,y }}\right)$. Since both hot wall temperature and bulk temperature are

345 function of the height from the bottom of the cell, $S$ varies with dimensionless height, $y / H$. In

346 Fig. 4, average stratification parameter, $S_{\text {ave }}=\left(T_{\text {top }}-T_{\text {bottom }}\right) /\left(\bar{T}_{\text {hot,y }}-\bar{T}_{\text {bulk,y }}\right)$, is indicated. For

347 single-phase cases, the $S_{\text {ave }}$ values ranged from 0.90 to 1.44 for the experimental runs listed in the

348 graph. Fig. 4(B) shows the bulk temperature profiles for two-phase natural convection for

349 various particle loadings. The graph shows the case of the bath temperature difference of $10{ }^{\circ} \mathrm{C}$

350 and the nominal particle size of $134 \mathrm{~mm}$. It can be seen that there is an inversion of temperature

351 gradient at bottom $(y / H=0.03)$ for the case of particle loading of $0.518 \mathrm{wt} \%$. This is because of

352 sediment layer of gelatin particles at the bottom of the cell.

Figs. 5 and 6 shows temperature contours measured along a vertical and horizontal line

354 for the single-phase and two-phase natural convection. The temperatures are plotted in a 355 dimensionless way as a ratio of the local temperature minus the cold wall temperature, $T-T_{\text {cold }}$, 356 to the hot wall temperature minus the cold plate temperature, $T_{\text {hot }}-T_{\text {cold }}$; that is, $357\left(T-T_{\text {cold }}\right) /\left(T_{\text {hot }}-T_{\text {cold }}\right)$. The distance $x$ is the distance from the hot end, and $L$ is the width of the 358 convection cell. The dimensionless length, $x / L$ indicates that lower values are closer to the hot 359 wall. Fig. 5 (top row) and (bottom row) show the temperature contours for single-phase case and two-phase case of particle size of $134 \mathrm{~mm}$ for various particle loadings. (Top row) is for bath 361 temperature difference of $10{ }^{\circ} \mathrm{C}$ and (bottom row) is for $20{ }^{\circ} \mathrm{C}$. From Fig. 5, for single-phase 362 case, the fluid within the natural convection cell is thermally stratified except in the thermal 363 boundary layers, where the temperature gradients are concentrated. For two-phase cases, the temperature contours are similar to single-phase case except in the sediment layer at bottom of 
365 the cell. For each two-phase case, the temperatures at the bottom, where the dimensionless

366 distance from the hot wall is close to zero, are high compared to single-phase case. The

367 temperature contours show inverted temperature stratification. These inverted contours

368 correspond to the extent of sedimentation along the bottom part of the experimental cell. The

369 different loadings gave rise to different sediment layer depths. From Fig. 5 (top row) for cases of

370 particle loading of $0.026 \mathrm{wt} \%$ and $0.518 \mathrm{wt} \%$, the temperature within the cell is higher than

371 single-phase case, whereas for cases of particle loading of $0.104 \mathrm{wt} \%$ and 0.260 wt $\%$,

372 temperature contours are similar to single-phase case. Fig. 6 (top row) and (bottom row) show

373 the temperature contours for single-phase case and two-phase case of particle size of $230 \mathrm{~mm}$ for

374 various particle loadings. (Top row) is for bath temperature difference of $10{ }^{\circ} \mathrm{C}$ and (bottom

375 row) is for $20^{\circ} \mathrm{C}$. From Fig. 4 (A), the temperature within the cell for two-phase cases is higher

376 than that of single-phase case. From Figure 6 (bottom row), the inverted contour due to sediment

377 layer of particles is seen for case of particle loading of $0.260 \mathrm{wt} \%$. For case of particle loading

378 of $0.026 \mathrm{wt} \%$, there is not major difference when it is compared with single-phase case. From

379 Figs. 5 and 6, it is difficult to see a detail temperature gradient near the hot wall since a steep

380 temperature gradient is concentrated in a very small range of $x / L$.

\section{Heat transfer characteristics}

Verification that the natural convection test cell can provide accurate measurements was

384 obtained by comparing measurements for single-phase natural convection with an accepted

385 correlation. For natural convection in enclosures, the mean value of the Nusselt number, $N u_{\mathrm{H}}$,

386 for aspect ratio [49], $A \sim 1$, and $10^{6}<R a_{\mathrm{H}} \leq 10^{12}$ as: 


$$
N u_{\mathrm{H}}=0.082 R a_{\mathrm{H}}^{0.329}
$$

$N u_{\mathrm{H}}[50]$ for $\left.1<A<2,10^{-3}<\operatorname{Pr}<10^{5}, 10^{3}<\operatorname{Pr} /(0.2+\operatorname{Pr})\right) R a_{H}(L / H)^{3}$ as:

$$
N u_{\mathrm{H}}=0.18\left(\frac{P r}{0.2+P r} R a_{\mathrm{H}}\right)^{0.29}\left(\frac{L}{H}\right)^{-0.13}
$$

394 where $R a_{\mathrm{H}}$ is the Rayleigh number based on the height of the convection cell, $H . N u_{\mathrm{H}}$ and $R a_{\mathrm{H}}$ 395 are defined as:

$$
N u_{\mathrm{H}}=\frac{1}{H} \int_{0}^{H} N u_{y} d y
$$

398

$$
R a_{\mathrm{H}}=\frac{g \beta\left(T_{\mathrm{hot}}-T_{\mathrm{cold}}\right) H^{3}}{v \alpha}
$$

400

401

In the present study, the aspect ratio, $A$, was 1.98 . The deviation between measurement 402 and correlation for this study is $2.54-15.9 \%$ from Eq. (1) and 0.11-30.3 \% from Eq. (2). If we 403 introduce the notation, " $s N u$ ", to represent the Nusselt number in stratified natural convection. 404 For natural convection of ordinary $\operatorname{Pr}$ fluid $(\operatorname{Pr} \geq 1)$, then [e.g. 45]:

405

$$
s N u \equiv \frac{N u}{(1+S)^{1 / 4}} \sim R a_{H}{ }^{1 / 4},
$$




$$
s N u \equiv \frac{N u}{(1+S)^{1 / 2}} \sim R a_{H}{ }^{1 / 4} \operatorname{Pr}^{1 / 4}
$$
421 particles.

It is worthwhile to note that the stratification parameter appears as part of a factor that modifies the non-stratified Nusselt number. The relationship correctly reduces to the non-stratified case when there is no stratification $(S=0)$.

The local Nusselt numbers were also obtained for two-phase natural convection. To form the local Nusselt number, $N u_{\mathrm{y}}$, and local Rayleigh number, $R a_{\mathrm{y}}$, properties of gelatin suspension were needed. Since gelatin particle loadings in this study were less than $1 \%$ by weight, properties of deionized water were used for all fluid properties for gelatin particle suspension. All physical properties of working fluid were evaluated at the film temperature, $T_{\text {film }}=\left(\bar{T}_{\text {hot }}+\bar{T}_{\text {cold }}\right) / 2$, where $\bar{T}_{\text {hot }}$ and $\bar{T}_{\text {cold }}$ are the mean temperature of the hot and cold walls, respectively. Fig. 7 shows the local Nusselt numbers for two-phase natural convection with respect to local Rayleigh numbers. The trendlines were obtained from single-phase experiments and are shown in the as a reference for the determination of enhancement/de-enhancement in the local Nusselt number of the two-phase natural convection due to the presence of the gelatin

Fig. 7 shows the variation for bath temperature difference of $10^{\circ} \mathrm{C}$ and $20^{\circ} \mathrm{C}$. (A) is for the nominal particle size of $134 \mu \mathrm{m}$ and (B) for $230 \mu \mathrm{m}$. (A) is for particle loading of 0.026 $\mathrm{wt} \%$, and (B) is for $0.26 \mathrm{wt} \%$. The noted values of particle loading indicate the percentage of the gelatin particles in suspension by weight. 0.026 corresponds to 5 grams of gelatin particle in the cell, which contains approximately 19.2 kilograms (20 liters) of deionized water. The vertical dash line at $R a_{\mathrm{y}}=10^{8}$ indicates the boundary between laminar and transition region. The vertical dash line at $R a_{\mathrm{y}}=10^{10}$ indicates the boundary between transition and turbulent region. In each 
429 figure, (II) is an enlargement of (I) from $10^{9} \leq R a_{\mathrm{y}} \leq 10^{11}$ and $100 \leq N u_{\mathrm{y}} \leq 1000$. That is, the 430 lowest measurement point influence by conduction heat transfer is discarded to effectively show 431 the convection heat transfer results.

From Fig. 7 (A) to (B), there is a reduction in local Nusselt number, $N u_{\mathrm{y}}$, at lower 433 Rayleigh number, $10^{6} \leq R a_{\mathrm{y}} \leq 10^{7}$ for both cases of bath temperature difference of 10 and $20^{\circ} \mathrm{C}$.

434 In transition region, $10^{9} \leq R a_{\mathrm{y}} \leq 10^{11}$, there is no significant change in $N u_{\mathrm{y}}$ between single- and 435 two-phase cases except for the case of nominal particle size of $230 \mathrm{~mm}$, particle loading of 0.260 $436 \mathrm{wt} \%$, and bath temperature difference of $20^{\circ} \mathrm{C}$. However, in turbulent region, $10^{10} \leq R a_{\mathrm{y}}$, the 437 data plots for two-phase cases show both increase and decrease in $N u_{\mathrm{y}}$. As it is seen in Fig. 7 438 (A)(II), there is an increase in $N u_{\mathrm{y}}$, compared to the reference line of single-phase natural 439 convection, for the case of bath temperature difference of $10^{\circ} \mathrm{C}$. However there is a decrease in $440 N u_{\mathrm{y}}$ for the case of bath temperature difference of $20^{\circ} \mathrm{C}$ especially at Rayleigh number of $5 \times 10^{10}$ 441 and $6 \times 10^{10}$. In Fig. 7 (B)(II), there is no significant difference between single- and two-phase 442 cases for the case of bath temperature difference of $10^{\circ} \mathrm{C}$. For the case of bath temperature 443 difference of $20^{\circ} \mathrm{C}$, the plots of $N u_{\mathrm{y}}$ are consistently below the reference line of single-phase 444 case. This can be due to the thermal stratification within the natural convection cell. Introducing 445 a scaling, or order of magnitude analysis, a heat transfer relationship incorporating the 446 stratification parameter, $S$, with $S=0$ for non-stratified case and $S>0$ for stratified case. Fig. 8 447 shows a graph of stratified Nusselt number and the Rayleigh number. Fig. 8 also shows 448 trendlines of ' $s N u_{y}$ vs. $R a_{\mathrm{y}}$ ' obtained for transition, and turbulent regime. The value of the 449 stratification factor depended on each experimental run and ranged from 0.9 to 1.44 . After 
thermal stratification was taken into account, the data points can be shifted closer to conventional data points and in such a case would show less spread than when stratification is not factored.

\section{Velocity profiles}

Velocity measurements were made using Met-Flow ultrasonic velocity profiler (UVP). The vertical velocity components were obtained in the vicinity of the hot wall. Three transducers, each with casing diameter of $8 \mathrm{~mm}$ (active diameter is $5 \mathrm{~mm}$ ) were used. The distance between the transducers was $12.7 \mathrm{~mm}$. The transducers were installed $103 \mathrm{~cm}$ above the bottom of the cell and were moved in a transverse direction towards the center of the cell at 1 to $4 \mathrm{~mm}$ intervals. Since the transducer has a diameter of $8 \mathrm{~mm}$, there is no data between 0 to 4 $\mathrm{mm}$ distances from the hot wall. The velocity measurements were taken in the range of $0.50 \leq y / H \leq 0.98$, where $y / H$ is the dimensionless height from the bottom. Below $y / H=0.50$, where the distance from the transducers were large, the profile has a lower measurement success rate than the higher value of $y / H$, since the echo is not sufficiently strong from the far side. Measurements made along the axis were spatially limited in range; this range is called the measurement window. The measurement window was $748 \mathrm{~mm}$ in this study. The window is divided into 128 measurement volumes. The length of each measuring volume along the axis of detection was chosen as $0.74 \mathrm{~mm}$. The velocity profiles are plotted against the distance from the hot wall at $y / H=0.944$ and 0.538 . At $\mathrm{y} / \mathrm{H}=0.944$ the convective flow at the hot wall is turbulent, while at $y / H=0.538$ the flow is in transition or turbulent region depending on conditions, such as, temperature distance between the hot wall and bulk temperature. The velocities obtained from UVP measurements were space and time averaged within the single measurement volume. The minimum velocity resolution used in this study was $0.72 \mathrm{~mm} / \mathrm{s}$. This 
473 means that the velocity obtained from measurements were in multiples of $0.72 \mathrm{~mm} / \mathrm{s}$, such as $4740.72,1.44$, and 2.16 . The velocity difference smaller than $0.72 \mathrm{~mm} / \mathrm{s}$ was not detectable. The 475 maximum averaged velocity obtained in this study was $7.2 \mathrm{~mm} / \mathrm{s}$. Since velocity is very small in 476 this study, the standard deviation is large. The standard deviation in velocity measurements 477 ranges $40 \%$ to $414 \%$. The error in the distance from the hot wall was taken as 1 millimeter. 478 Figs. 8-9 (A) and (B) show the comparison of velocity profiles between single-phase and two479 phase flows. For two-phase case, the particle loading is $0.260 \mathrm{wt} \%$ and particle size is $134 \mu \mathrm{m}$. 480 (A) is the velocity profiles at dimensionless height, $y / H$, of 0.944 and (B) is for 0.538 . In each 481 figure, (I) is for bath temperature of $10^{\circ} \mathrm{C}$ and (II) is for $20^{\circ} \mathrm{C}$. From Fig. 8 - (A) there is no 482 significant difference between single-phase and two-phase cases when error bars are taken into 483 account. However, the plots for two-phase case in (II) are smaller in the range of $4 \mathrm{~mm} \leq x \leq 11$ 484 mm. In Fig. 8-9 (B) the difference between single- and two-phase cases can be seen at $23 \mathrm{~mm} \leq$ $485 x \leq 32 \mathrm{~mm}$. For the case of bath temperature difference of $10^{\circ} \mathrm{C}$, the velocity of two-phase case 486 is larger than single-phase case at $23 \mathrm{~mm} \leq x$. However for the case of temperature difference of $48720{ }^{\circ} \mathrm{C}$, the velocity of two-phase case is smaller at $23 \mathrm{~mm} \leq x \leq 25 \mathrm{~mm}$.

\section{Implications}

Hoffman et al. [14, 15, 40] showed that temperature sensitive gels could be used to selectively or non-selectively remove undesirable toxins, to assay for specific substances, and to 492 recover selected products of a biochemical process. This process may also be applied in a non493 biochemical situation. The basis of the model proposed in this study is formulated from 494 Hoffman et al. [14, 15, 40]. The schematic illustration of this study's proposed model 495 entrapment process is as shown in Fig. 910(A). The entrapment process illustrated in Fig. 


\section{Conclusions}

910(A) thus forms a foundation for a rudimentary filtering system. In this situation, the Dynamic Filtering System or DFS (see Fig. 910(B)), dried temperature sensitive gels are immersed into a natural convection cell (step 1), which may contain mixed waste effluents with targeted particles. Opposite walls of the enclosure are heated and cooled. The gels absorb wastewater and swell with increasing temperature (swollen state) denoted by step (2). If the wastewater contains radioactive materials, then a probable scene, is one in which the radioactive waste particles adhere to this low-cost gel-like material. The gels then undergo volumetric transition and collapse when they are cooled below the LCST (step 3). In this collapsed state, the gels will release only water and encapsulate the solid particulates. In step (4), gels, which captured solid particles, sink to the bottom of the convection cell as they become denser than the carrier fluid. Finally, the waste stream is drained and the gel-sediment mix, which trapped radioactive solid particles, are collected for eventually semi-dry storage or disposition. In order to realize this Dynamic Filtering System (DFS), a fundamental understanding of the nature of the temperature sensitive gel materials, as well as the natural convection of temperature sensitive gel would be needed.

Measurements of temperature and velocity were carried out in order to obtain a better understanding of heat transfer characteristics of gelatin particle as a surrogate to thermally transitioning polymer gel particles that would potentially aid in extraction of radioactive particles in mixed waste. Although the ultimate goal of this study was to evaluate dynamic filtering capability of mixed waste streams with thermally transitioning polymer gel particles, especially 
518 radioactive particulates and potentially heavy metals, a fundamental understanding first of

519 natural convection of a hydrophilic particle-laden suspension was investigated. In this study

520 gelatin was used for experiments. Although hydrophilic, since the solid density of gelatin

521 particles in the water was larger than that of water, the gelatin particles gradually settled out of

522 suspension.

523 The heat transfer result comparing single-phase and two-phase natural convection 524 revealed the effect of particles on natural convection heat transfer. Heat transfer results with and

525 without particles showed both enhancement and de-enhancement in Nusselt number, depending 526 on bath temperature difference and particle size as follows:

527 1) There was no significant change in heat transfer when particle loading was varied.

528 2) In general, for the case of bath temperature difference of $10^{\circ} \mathrm{C}$ and particle size of 134

$529 \mu \mathrm{m}$, there was an enhancement in heat transfer whereas for bath temperature difference

$530 \quad$ of $20^{\circ} \mathrm{C}$, there was a de-enhancement in heat transfer.

531

3) For the case of particle size of $230 \mu \mathrm{m}$, there was more de-enhancement in heat transfer compared with the case of particle size of $134 \mu \mathrm{m}$.

534 Acknowledgments

We would like to extend our sincerest gratitude to Dan Estel (MST Reactor), Jason Hall, and affiliated staff at MST Reactor facility for construction of equipment used in this study. We

537 also would like to acknowledge Dr. David Wronkiewicz for help in sieving and particle size 538 analysis of the gelatin particles. 


\begin{tabular}{|c|c|}
\hline Symbol & Description \\
\hline A & Aspect ratio $[\mathrm{H} / \mathrm{L}]$ \\
\hline $\mathrm{c}$ & Velocity of ultrasound in the two-phase flow \\
\hline $\bar{d}$ & Number-average particle diameter \\
\hline$d_{\mathrm{p}}$ & Gelatin particle size $(\mu \mathrm{m})$ \\
\hline$f_{\mathrm{i}}$ & Fraction in the class range \\
\hline$f_{\mathrm{d}}$ & Doppler frequency shift \\
\hline$f_{0}$ & Ultrasound frequency \\
\hline$g$ & Gravitational acceleration $\left(\mathrm{m} / \mathrm{s}^{2}\right)$ \\
\hline$H$ & The distance between two horizontal walls \\
\hline$k$ & Thermal conductivity $(\mathrm{W} / \mathrm{m} \cdot \mathrm{K})$ \\
\hline$L$ & The distance between hot and cold walls \\
\hline$L_{1}$ & Thickness of the aluminum tube wall \\
\hline$L_{2}$ & Thickness of the aluminum tape \\
\hline$n_{\mathrm{i}}$ & Number of particles \\
\hline$N u$ & Nusselt number $[h H / k]$ \\
\hline$N u_{\mathrm{y}}$ & Local Nusselt number $[h y / k]$ \\
\hline $\operatorname{Pr}$ & Prandtl number $[v / \alpha]$ \\
\hline$q_{x}^{\prime \prime}$ & Heat flux at $\mathrm{x}\left(\mathrm{W} / \mathrm{m}^{2}\right)$ \\
\hline$R a$ & Rayleigh number $\left[g \beta \Delta T H^{3} / v \alpha\right]$ \\
\hline$R a_{\mathrm{H}}$ & Rayleigh number based on the cell height $H\left[g \beta \Delta T H^{3} / v \alpha\right]$ \\
\hline $\mathrm{Ra}_{\mathrm{y}}$ & Local Rayleigh number $\left[g \beta \Delta T y^{3} / v \alpha\right]$ \\
\hline$S$ & Stratification parameter $\left[\left(T_{\text {top }}-T_{\text {bottom }}\right) /\left(T_{\text {wall, } y}-T_{\text {bulk,y }}\right)\right]$ \\
\hline$S_{\text {ave }}$ & Average stratification parameter \\
\hline$s N u_{\mathrm{y}}$ & Local stratified Nusselt number $\left[N u_{\mathrm{y}} /(1+S)^{1 / 4}\right]$ \\
\hline$t$ & Time lapse between the emission and reception of ultrasound pulses \\
\hline$T$ & Local temperature in ${ }^{\circ} \mathrm{C}$ \\
\hline
\end{tabular}




\begin{tabular}{|ll|}
\hline$T_{\text {bottom }}$ & Bulk temperature at the bottom of the cell $\left({ }^{\circ} \mathrm{C}\right)$ \\
$T_{\text {bulk }}$ & Bulk temperature $\left({ }^{\circ} \mathrm{C}\right)$ \\
$T_{\text {cold }}$ & Cold wall temperature $\left({ }^{\circ} \mathrm{C}\right)$ \\
$T_{\text {film }}$ & Film temperature, $\left[\left(\bar{T}_{\text {hot }}+\bar{T}_{\text {cold }}\right) / 2\right]\left({ }^{\circ} \mathrm{C}\right)$ \\
$T_{\text {hot }}$ & Hot wall temperature $\left({ }^{\circ} \mathrm{C}\right)$ \\
$T_{\text {inside }}$ & Inside surface temperature of the aluminum tube $\left({ }^{\circ} \mathrm{C}\right)$ \\
$T_{\text {surface }}$ & Surface temperature of the aluminum tube $\left({ }^{\circ} \mathrm{C}\right)$ \\
$\Delta T$ & Temperature difference $\left[T_{\text {hot }}-T_{\text {cold }}\right]\left({ }^{\circ} \mathrm{C}\right)$ \\
$T_{\text {top }}$ & Bulk temperature at the top of the cell $\left({ }^{\circ} \mathrm{C}\right)$ \\
$T_{\text {wall }}$ & Wall temperature $\left({ }^{\circ} \mathrm{C}\right)$ \\
$\bar{T}_{\text {bulk }}$ & Average bulk temperature $\left({ }^{\circ} \mathrm{C}\right)$ \\
$\bar{T}_{\text {cold }}$ & Average cold wall temperature $\left({ }^{\circ} \mathrm{C}\right)$ \\
$\bar{T}_{\text {hot }}$ & Average hot wall temperature $\left({ }^{\circ} \mathrm{C}\right)$ \\
$u$ & Fluid velocity component perpendicular to the hot wall \\
$\mathrm{u}_{\mathrm{p}}$ & Velocity of the particles within the convective cell \\
\hline
\end{tabular}

542 Greek letters

\begin{tabular}{|l|l|}
\hline Symbol & Description \\
\hline$\alpha$ & Thermal diffusivity $\left(\mathrm{cm}^{2} / \mathrm{s}\right)$ \\
$\beta$ & Thermal expansion coefficient $\left(\mathrm{K}^{-1}\right)$ \\
$\sigma$ & Standard deviation \\
\hline
\end{tabular}




\section{References}

545

546

547

548

549

550

551

552

553

554

555

556

557

558

559

560

561

562

563

564

565

566

567

568

569

570

571

572

573

574
[1] Reinert, K. H., Riskbased cleanup levels for soils. Superfund '90, Hazardous Materals Control Research Inst., Washington, D.C., (1990) 185-188.

[2] Higgins, A., Lagrega, M. D., Methods to set cleanup goals to protect surface and ground water quality at hazardous waste sites. Water Science and Technology 23, (1991) 405412.

[3] Wanty, R. B., Rice, C. A., Langmuir, D., Briggs, P. H., Lawrence, E. P., Prediction of uranium adsorption by crystalline rocks; The key role of reactive surface area. Mat. Res. Soc. Sympo. Proc. (1991) 212, 695-702.

[4] Wanty, R. B., Nordstrom, D. K., Natural radioniculides; In regional ground-water quality, Alley, W. M., (ed.). Van Nostrand Reinhold, New York. (1993).

[5] Tanaka, T., Collapse of gels and the critical end point. Phys. Rev. Lett. 40, (1978) 820-823.

[6] Tanaka, T., Gels. Sci. Am. 244, (1981) 124-138.

[7] Tanaka, T., Fillmore, D., Sun, S. T., Nishino, I., Swislow, G., Shah, A., Phase transition in ionic gels. Phys. Rev. Lett. 45, (1980) 1636-1639.

[8] Tanaka, T., Nishino, I., Sun, S. T., Ueno, S., Collapse of gels in an electric-field. Science 218, (1982) 467-469.

[9] Hirokawa, T., Tanaka, T., Volume phase transition in nonionic gel. J. Chem. Phys. 81, (1982) 6379-6380.

[10] Ohmine, I., Tanaka, T., Salt effects on the phase-transition of ionic gels. J. Chem. Phys. $77,(1982) 5725-5729$.

[11] Katayama, S., Hirokawa, Y., Tanaka, T., Reentrant phase transition in acrylamidederivative copolymer gels. Macromolecules 17, (1984) 2461-2463.

[12] Irie, M., Kunwatchakun, D., Photoresponsive Polymers; Reversible photostimulate dilation of polyacrylamide gels having triphenylmethane leuco derivatives. Macromolecules 19, (1986) 2476-2480.

[13] Gehrke, S. H., Andrews G.P. Cussler, E. L., Chemical aspects of gel extraction. Chemical Engineering Science 41, (1986) 2153-2160.

[14] Hoffman, A. S., Afrassiabi, A., Dong, L. C., Delivery and removal of substances to and from surrounding suspensions using thermally reversible hydrogels. Macromolecular Preprints-IUPAC Macro '86, (1986a ) 65-66. 
[15] Hoffman, A. S., Afrassiabi, A., Dong, L.C., Thermally reversible hydrogels; II. Delivery and selective removal of substances from aqueous suspensions. J. Controlled Release 4, (1986b) 213-222.

[16] Freitas, R. F. S., Cussler, E. L., Temperature Sensitive Gels as Extraction Solvents, Chemical Engineering Science 42, (1987) 97-103.

[17] Trank, S. J., Johnson, D.W., Cussler, E. L., Isolated soy protein using temperature-sensitive gels. Food Technol. 43, (1989) 78-83.

[18] Feil, H., Bue, Y.H., Feijen, J., Kim, S.W., Molecular separation by thermosensitive hydrogel membranes. Journal of Membrane Science 64, (1991) 283-294.

[19] Yoshida, R., Sakai, K., Okano, T., Sakurai, Y., Pulsatile drug delivery systems using hydrogels. Advanced Drug Delivery Reviews 11, (1993) 85-108.

[20] Koyaguchi, T., Hallworth, M A., Huppert, H. E., Sparks, R. S. J., Sedimentation of particles from a convecting fluid. Nature 343, (1990) 447-450.

[21] Stommel, H., Trajectories of small bodies sinking slowly through convection cells, Journal of Marine Research 8, (1949) 24-29.

[22] Bartlett, R. W., Magma convection, temperature distribution, and differentiation, American Journal of Science 267, (1969) 1067-1082.

[23] Huppert, H. E., Sparks, S. J., The fluid dynamics of a basaltic magma chamber replenished by influx of hot, dense ultrabasic magma. Contributions to Mineralogy and Petrology 75, (1980) 279-289.

[24] Marsh, B. D., Maxey, M. R., On the distribution and separation of crystals in convecting magma, Journal of Volcanology and Geothermal Research 24, (1985) 95-150.

[25] Weinstein, S. A., Yuen, D. A., Olson, P. L., Evolution of crystal-settling in magmachamber convection. Earth and Planetary Science Letters 87, (1987) 237-248.

[26] Huppert, H. E., Kerr, R. C., Lister, J. R., Turner, J. S., Convection and particle entrainment driven by differential sedimentation. J. Fluid Mech 226, (1991) 349-369.

[27] Kerr, R. C., Lister, J. R., Further results for convection driven by the differential sedimentation of particles. J. Fluid. Mech. 243, (1992) 227-245.

[28] Ungarish, M., Hydrodynamics of suspensions; Fundamentals of centrifugal and gravity separation, Springer-Verlag, New York. (1993). 
[29] Nicolai, H., Herzhaft, B., Hinch, E.J., Oger, L., Guazzelli, E., Particle velocity fluctuations and hydrodynamics; Self-diffusion of sedimenting non-Brownian spheres, Phys. Fluids 7 , (1995) 12-23.

[30] Cardoso, S. S. S., Woods, A. W., On convection and mixing driven by sedimentation. J. Fluid Mech. 285, (1995) 165-180.

[31] Davis, R. H., Velocities of sedimenting particles in suspensions. Advances in Fluid Mechanics, Tory, E. M. (ed.), Computational Mechanics Publications, Boston 7. (1996).

[32] Peysson, Y., Guazzelli, É., An experimental investigation of the intrinsic convection in a sedimenting suspension. Phys. Fluids 10 (1), (1997) 44-54.

[33] Özbelge, T. A., Heat transfer enhancement in turbulent upward flows of liquid-solid suspensions through vertical annuli. Int. J. Heat Mass Transfer 44, (2001) 3373-3379.

[34] Murray, D.B., Local enhancement of heat transfer in a particulate cross flow-I, Int. J. Multiphase Flow 20, (1994) 493-504.

[35] Plass, L., Molerus, O., Simultane Wärmeübergangs- und druck-verlustmessungen an feststoff/flüssigkeits-suspensionen im übergangsbereich vom homogenen zum heterogenen suspensions-transport. Chemie-Ing.-Techn. 46, (8), (1974) 355.

[36] Zisselmar, R., Molerus, O., Investigation of solid-liquid pipe flow with regard to turbulence modification. The Chemical Engineering Journal 18, (1979) 233-239.

[37] Keblinski, P., Phillpot, S., Choi, S.U.S., Eastman, J.A., Mechanisms of heat flow in suspensions of nano-sized particles (nanofluids). Int. J. Heat Mass Transfer 45, (2002) 855-863.

[38] Khanafer, K., Vafai, K., Lightstone, M., Buoyancy-driven heat transfer enhancement in a two-dimensional enclosure utilizing nanofluids. Int. J. Heat Mass Transfer 46, (2003) 3639-3653.

[39] Hattori, A., Okada, M., Kang, C., Natural convection of water-fine particles suspension in a rectangular vessel heated and cooled from opposing vertical walls (Effect of initial distribution of particle concentration) (in Japanese). Transaction of JSME B 67, (2001) 145-152.

[40] Hoffman, A.S., Applications of thermally reversible hydrogels in therapeutics and diagnostics. J. Controlled Release 6, (1987) 297-305.

[41] Rahman, S., Food properties handbook. CRC Press. (1995).

[42] Phelps, G. W., Particle size analysis : theoretical and practical aspects: United Clay Mines Corporation., (1958). 
653

654

655

656
[43] Jelínek, K. Z., Particle size analysis Translation editor: Bryce, W.A.J., (ed.), Halsted Press New York. (1974).

[44] Barth, H. G., (ed.) Modern methods of particle size analysis. Wiley, New York. (1984).

[45] Lykoudis, P. S., Tokuhiro, A. T., 1993. Natural convection over a vertical heated flat plate with gas injection and in the presence of a magnetic field. Advances in Turbulence Studies, Herman Branover \& Yeshajahu Unger (eds.), Progress in Astronautics and Aeronautics, Vol. 149, pp. 601-625. American Institute of Aeronautics \& Astronautics (AIAA), Inc., Salem, Massachusetts, USA.

[46] Takeda, Y., Development of an Ultrasound Velocity Profile Monitor. Nuclear Engineering and Design 126, (1991) 277-284.

[47] Takeda, Y., Velocity profile measurement by Ultrasonic Doppler Method. Experimental Thermal and Fluid Science 10, (1995 ) 444-453.

[48] Bejan, A., Convection heat transfer. $2^{\text {nd }}$ ed., Wiley, New York. (1995).

[49] Markatos, N. C., Pericleous, K. A., 1984. Laminar and turbulent natural convection in an enclosed cavity. Int. J. Heat Mass Transfer 27, 755-772.

[50] Berkovsky, B. M., Polevikov, V. K., 1976. Numerical study of problems on high-intensive free convection. Heat transfer and turbulent buoyant convection, volume II, Spalding, D. B., Afgan, N. (ed.), McGraw-Hill, New York. 


\section{List of Figures}

Figure 1: Schematic diagram of experimental setup for temperature measurement showing positioning of thermocouples and direction of water flow.

Figure 2: Diagram of temperature gradient between aluminum channel wall and aluminum tape.

Figure 3: Schematic picture of UVP velocity profile measurement on the hot wall of the natural convection cell.

Figure 4: Bulk temperature profiles. (A) is for single-phase and (B) is for two-phase. For (B), the bath temperature difference is $10{ }^{\circ} \mathrm{C}$ and particle size is $134 \underline{\mu}-\mathrm{m} . y / H$ is the dimensionless height from the bottom of the cell. $\Delta T$ is the difference in the mean values of the hot and cold wall temperatures obtained from the relation $\Delta T=\bar{T}_{\text {hot }}-\bar{T}_{\text {cold }} . S_{\text {ave }}$ is averaged stratification parameter and obtained from $\left(T_{\text {top }}-T_{\text {bottom }}\right) /\left(\bar{T}_{\text {hot,y }}-\bar{T}_{\text {bulk,y }}\right)$.

Figure 5: Temperature contours for single-phase flow and two-phase flow for particle size of $134 \mu \mathrm{m}$ at $\Delta T_{\text {bath }}=10^{\circ} \mathrm{C}$ (top row) and $\Delta \mathrm{T}_{\text {bath }}=20^{\circ} \mathrm{C}$ (bottom row) and for various particle loadings.

Figure 6: Temperature contours for gelatin particle size of, $\mathrm{d}_{2}=230 \mu \mathrm{m}$. at $\Delta T_{\text {Bath }}=10^{\circ} \mathrm{C}$ (top row) and $\Delta T_{\text {Bath }}=20^{\circ} \mathrm{C}$ (bottom row). For two-phase cases, the particle loadings are $0.026 \mathrm{wt} \%$ and 0.260 wt $\%$.

Figure 7: Graph of Nusselt numbers against Rayleigh numbers for the two-phase flow. (A) (I) shows the variation for bath temperature difference of $10^{\circ} \mathrm{C}$ and $20^{\circ} \mathrm{C}$ for particle size of $134 \mu \mathrm{m}$. The particle loading is $0.026 \mathrm{wt} \%$. (A) (II) is an enlargement of (A) (I) from $10^{9} \leq R a_{\mathrm{y}} \leq 10^{11}$ and $100 \leq N u_{\mathrm{y}} \leq$ 1000. The decrease in Nusselt number is seen at the lower Rayleigh number, $10^{6} \leq R a_{\mathrm{y}} \leq 10^{7}$. The lower the bath water temperature difference, the higher the value of $N u_{\mathrm{y}}$. (B) (I) shows the variation for bath temperature difference of $10^{\circ} \mathrm{C}$ and $20^{\circ} \mathrm{C}$ for particle size of $230 \mu \mathrm{m}$. The particle loading is $0.26 \mathrm{wt} \%$. (B) (II) is an enlargement of (B) (I) from $10^{9} \leq R a_{\mathrm{y}} \leq 10^{11}$ and $100 \leq N u_{\mathrm{y}} \leq 1000$. The decrease in Nusselt number is seen at the lower Rayleigh number, $10^{6} \leq R a_{\mathrm{y}} \leq 10^{7}$. The lower the bath water temperature difference, the higher the value of $N u_{\mathrm{y}}$.

Figure 8: Graph of stratified Nusselt numbers against Rayleigh numbers for two-phase natural convection. (I) and (II) show the variation for bath temperature difference of $10{ }^{\circ} \mathrm{C}$ and $20{ }^{\circ} \mathrm{C}$ for the nominal particle size of $134 \mu \mathrm{m}$ and $230 \mu \mathrm{m}$. (I) is for particle loading of $0.026 \mathrm{wt} \%$ and (II) is for $0.260 \mathrm{wt} \%$.

Figure 9: (A). Velocity profiles for single- and two-phase flows at $y / H=0.944$. For two-phase case, particle size is $134 \mu \mathrm{m}$ and particle loading is $0.26 \mathrm{wt} \%$. (A)(I) is for bath temperature difference of $10^{\circ} \mathrm{C}$ and (A)(II) is for $20^{\circ} \mathrm{C}$. (B). Velocity profiles for single- and two-phase flows at $y / H=0.538$. For two-phase case, particle size is $134 \mu \mathrm{m}$ and particle loading is $0.26 \mathrm{wt} \%$. (B)(I) is for bath temperature difference of $10{ }^{\circ} \mathrm{C}$ and (B)(II) is for $20^{\circ} \mathrm{C}$.

Figure 10: (A) Schematic of gelatin particle with volumetric phase transition and interaction with solid particles. (B) Schematic of proposed Dynamic Filtering System (DFS). LCST denotes lower critical suspension temperature. 


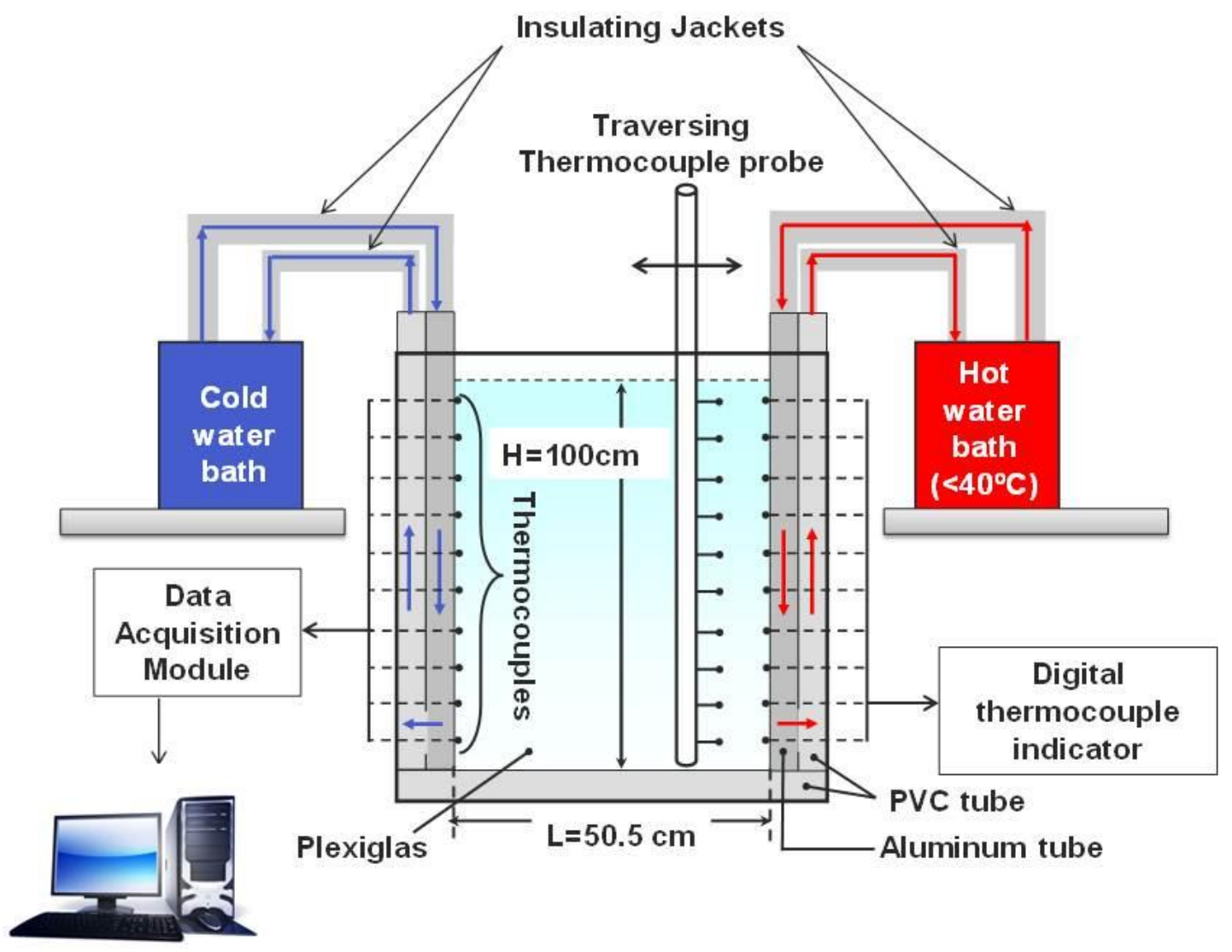

Figure 1: Schematic diagram of experimental setup for temperature measurement showing positioning of thermocouples and direction of water flow. 


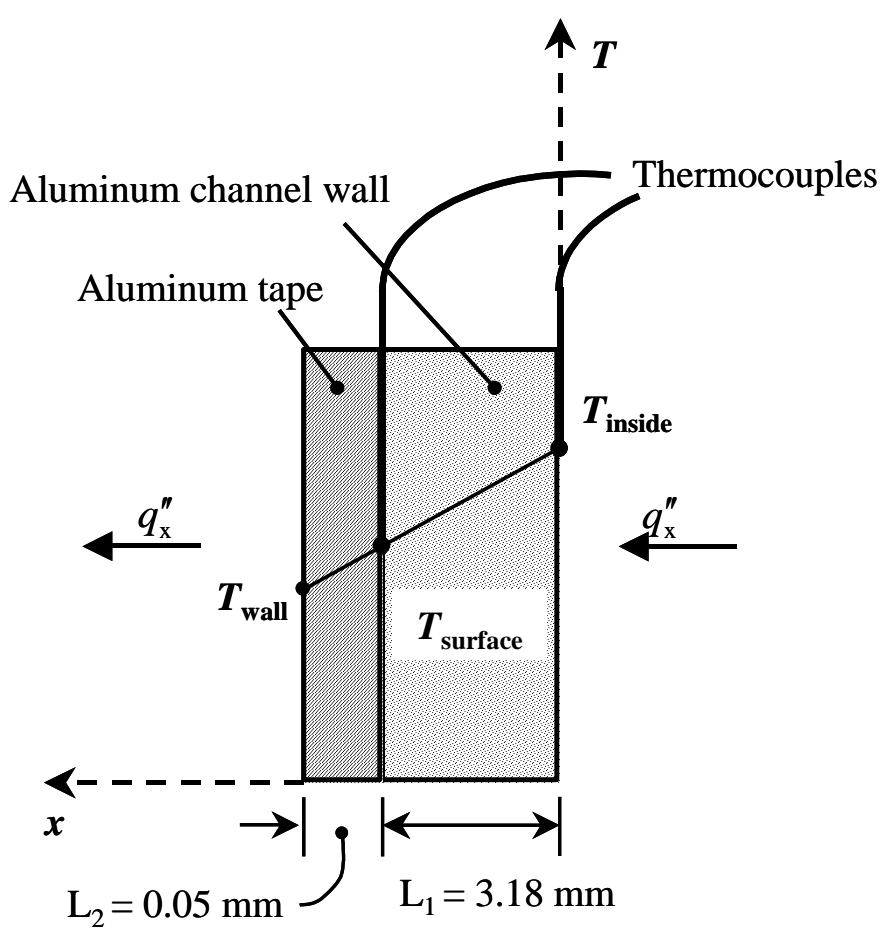

Figure 2: Diagram of temperature gradient between aluminum channel wall and aluminum tape. 


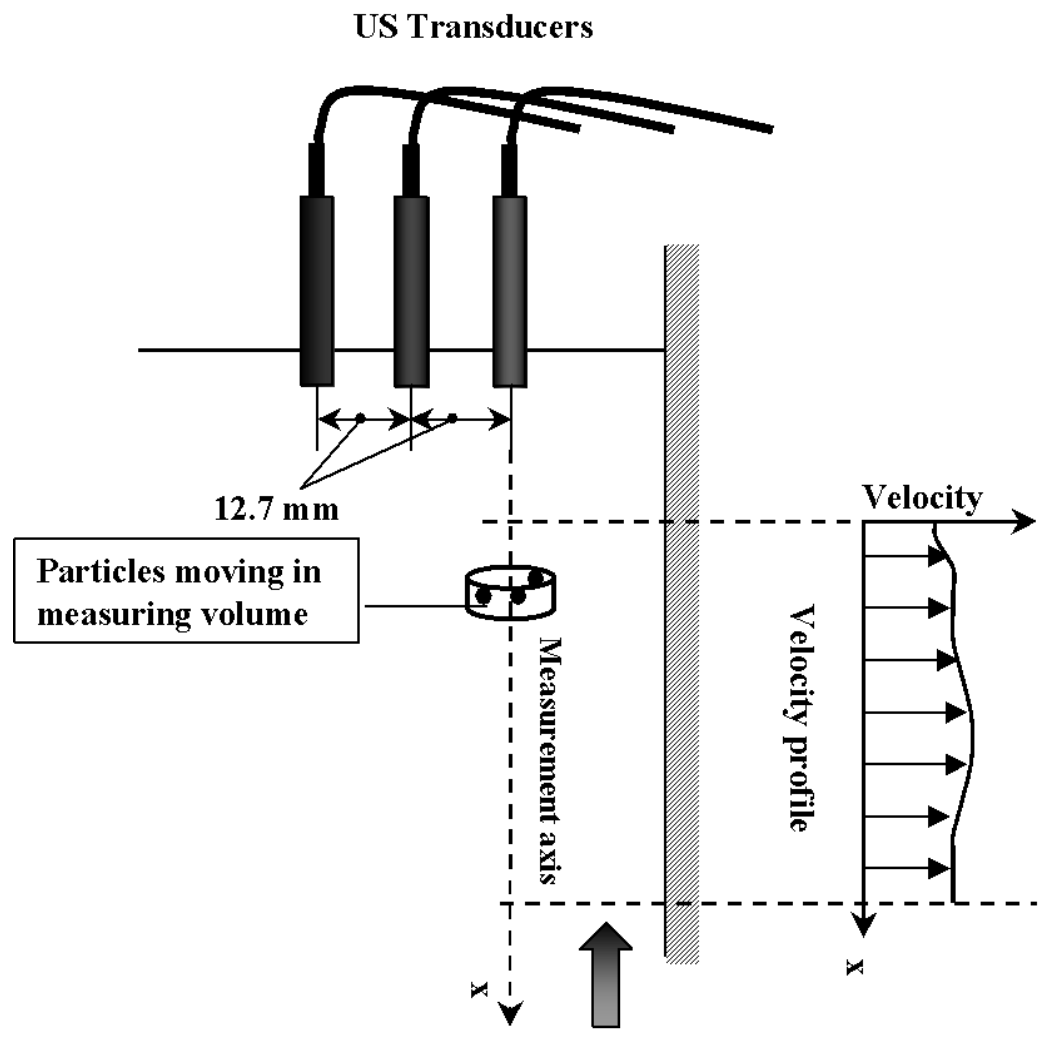

Flow direction

Figure 3: Schematic picture of UVP velocity profile measurement on the hot wall of the natural convection cell. 

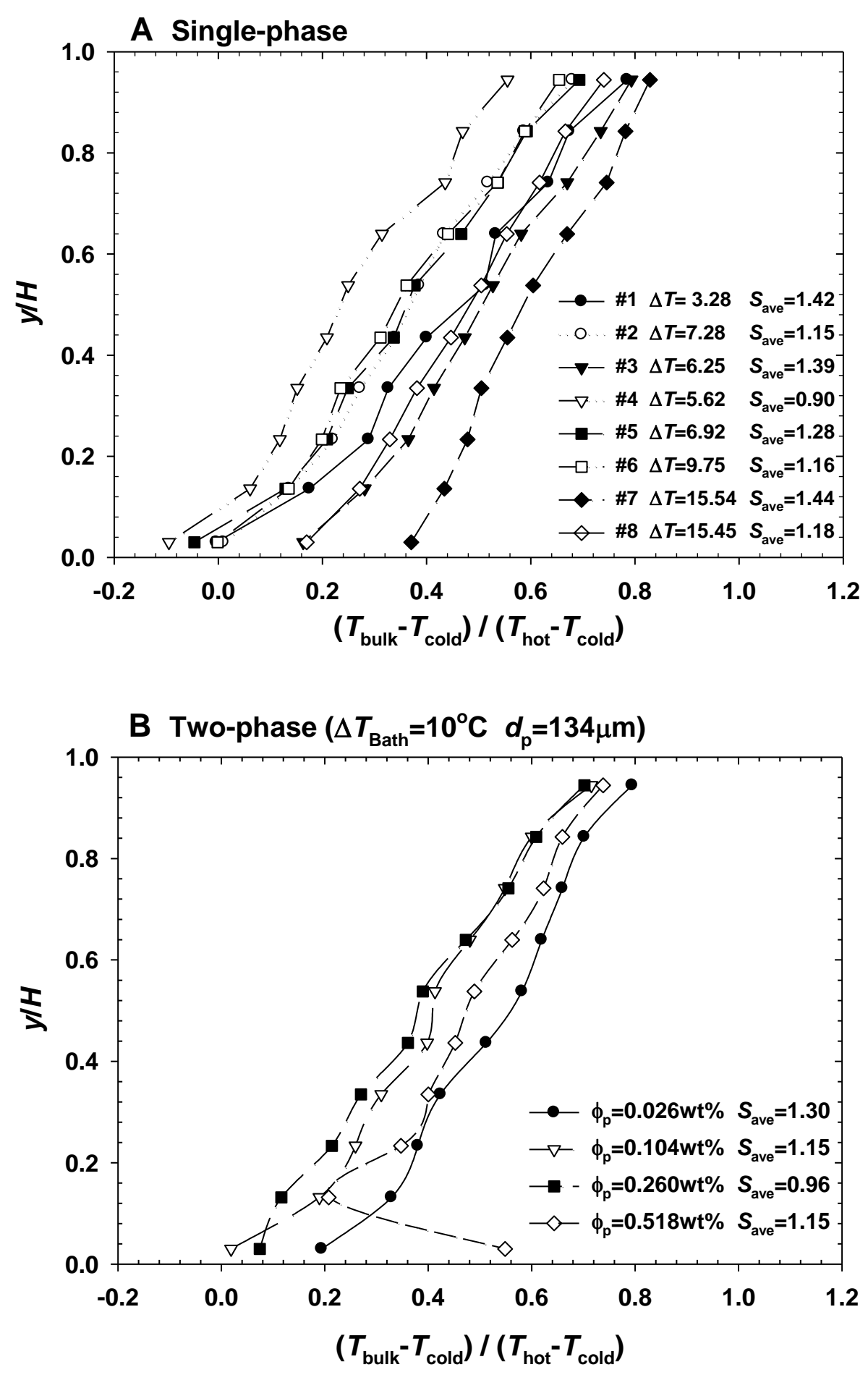

Figure 4. Bulk temperature profiles. (A) is for single-phase and (B) is for two-phase. For (B), the bath temperature difference is $10^{\circ} \mathrm{C}$ and particle size is $134 \mu \mathrm{m} . y / \mathrm{H}$ is the dimensionless height from the bottom of the cell. $\Delta T$ is the difference in the mean values of the hot and cold wall temperatures obtained from the relation $\Delta T=\bar{T}_{\text {hot }}-\bar{T}_{\text {cold }} . S_{\text {ave }}$ is averaged stratification parameter and obtained from $\left(T_{\text {top }}-T_{\text {bottom }}\right) /\left(\bar{T}_{\text {hot, },}-\bar{T}_{\text {bulk,y }}\right)$. 




Figure 5: Temperature contours for single-phase flow and two-phase flow for particle size of $134 \mu \mathrm{m}$ at $\Delta T_{\text {bath }}=10^{\circ} \mathrm{C}$ (top row) and $\Delta T_{\text {bath }}=20^{\circ} \mathrm{C}$ (bottom row) and for various particle loadings. 


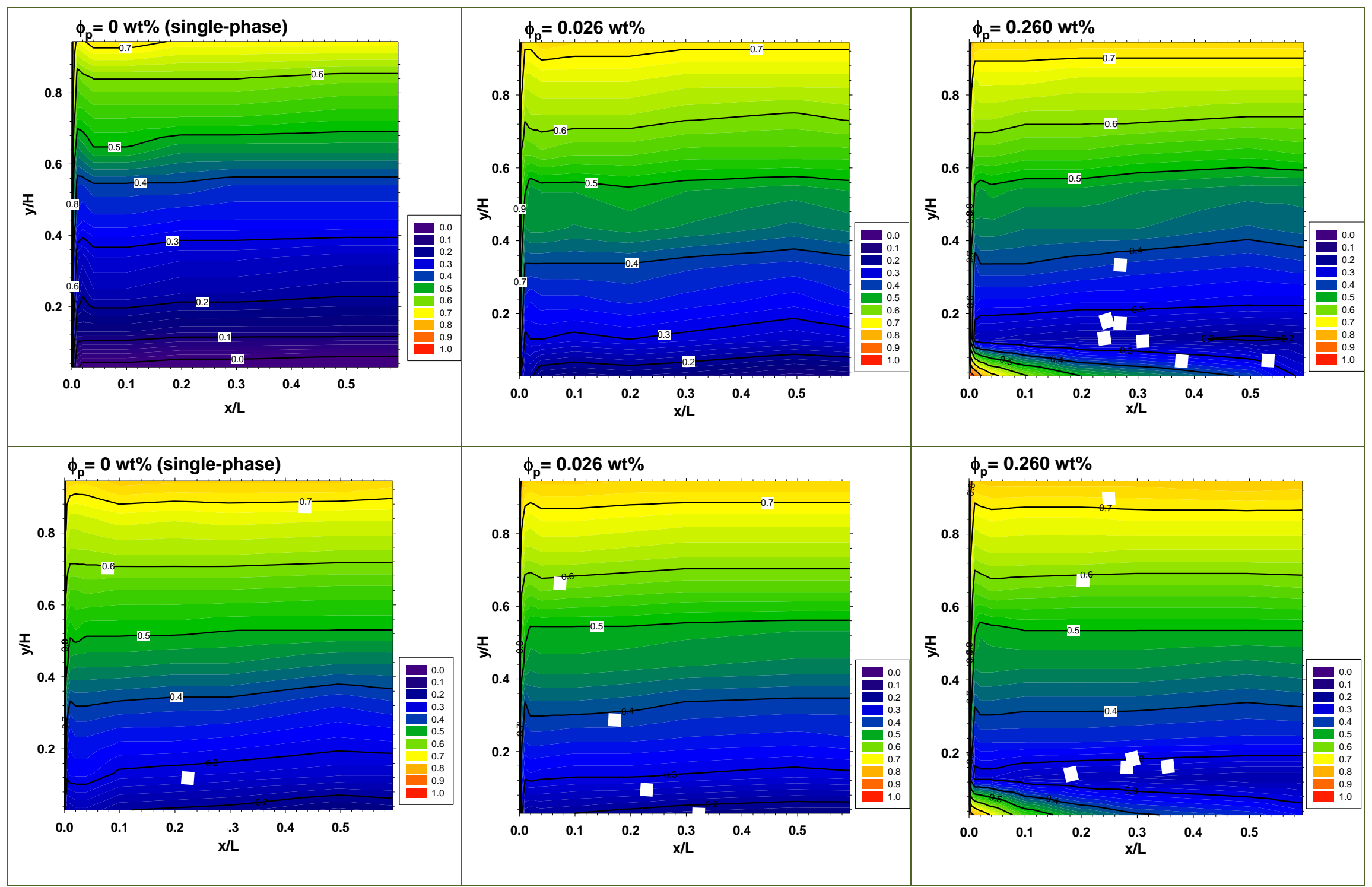

Figure 6: Temperature contours for gelatin particle size of, $\mathrm{d}_{2}=230 \mu \mathrm{m}$. at $\Delta T_{\text {Bath }}=10^{\circ} \mathrm{C}$ (top row) and $\Delta T_{\text {Bath }}=20^{\circ} \mathrm{C}$ (bottom row). For twophase cases, the particle loadings are $0.026 \mathrm{wt} \%$ and $0.260 \mathrm{wt} \%$. 

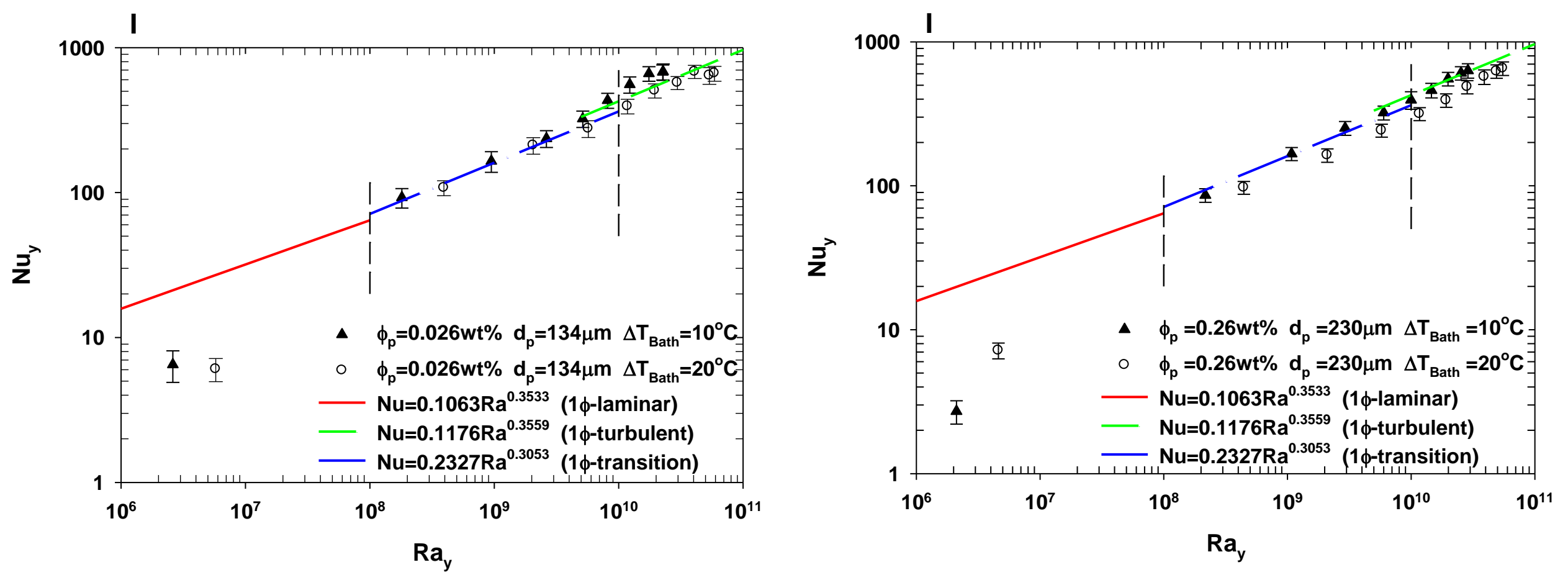

(A)(II)
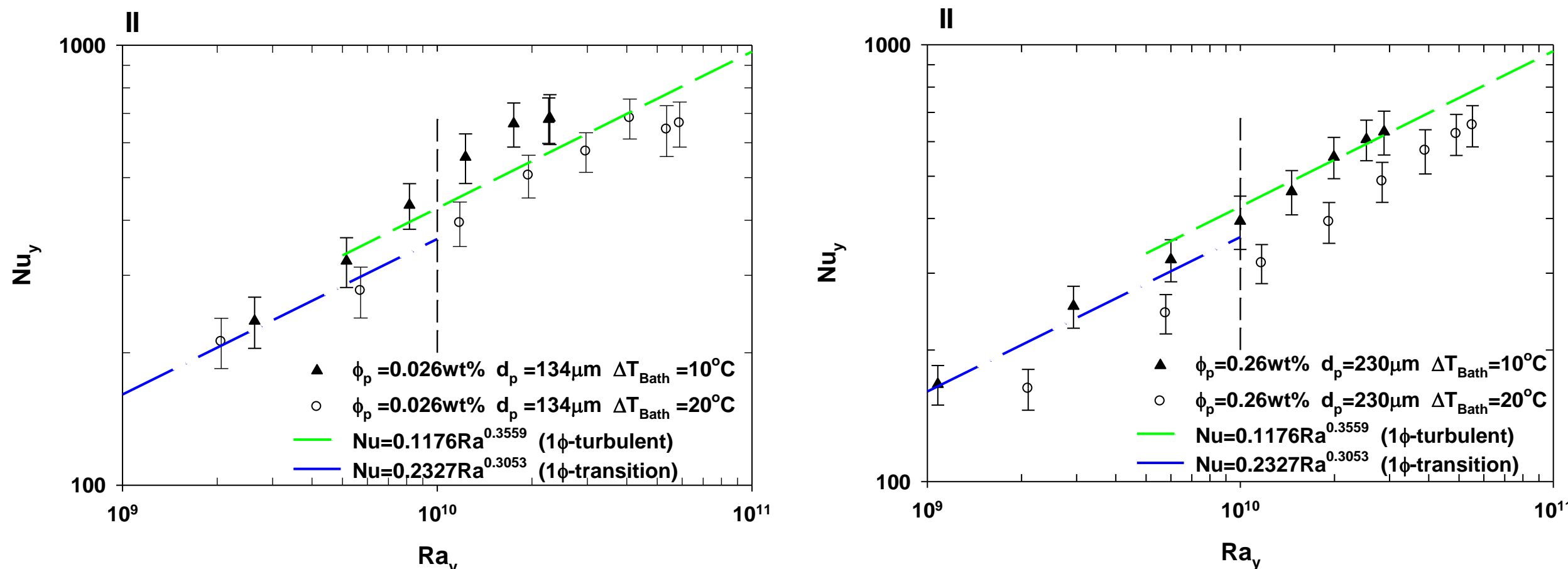

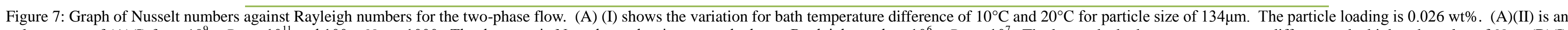

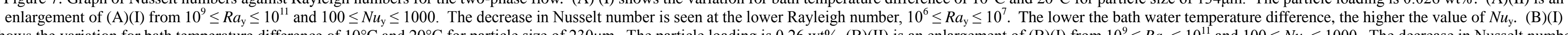

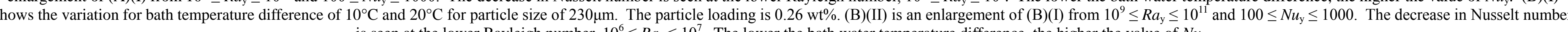
is seen at the lower Rayleigh number, $10^{6} \leq R a_{y} \leq 10^{7}$. The lower the bath water temperature difference, the higher the value of $N u_{y}$ 

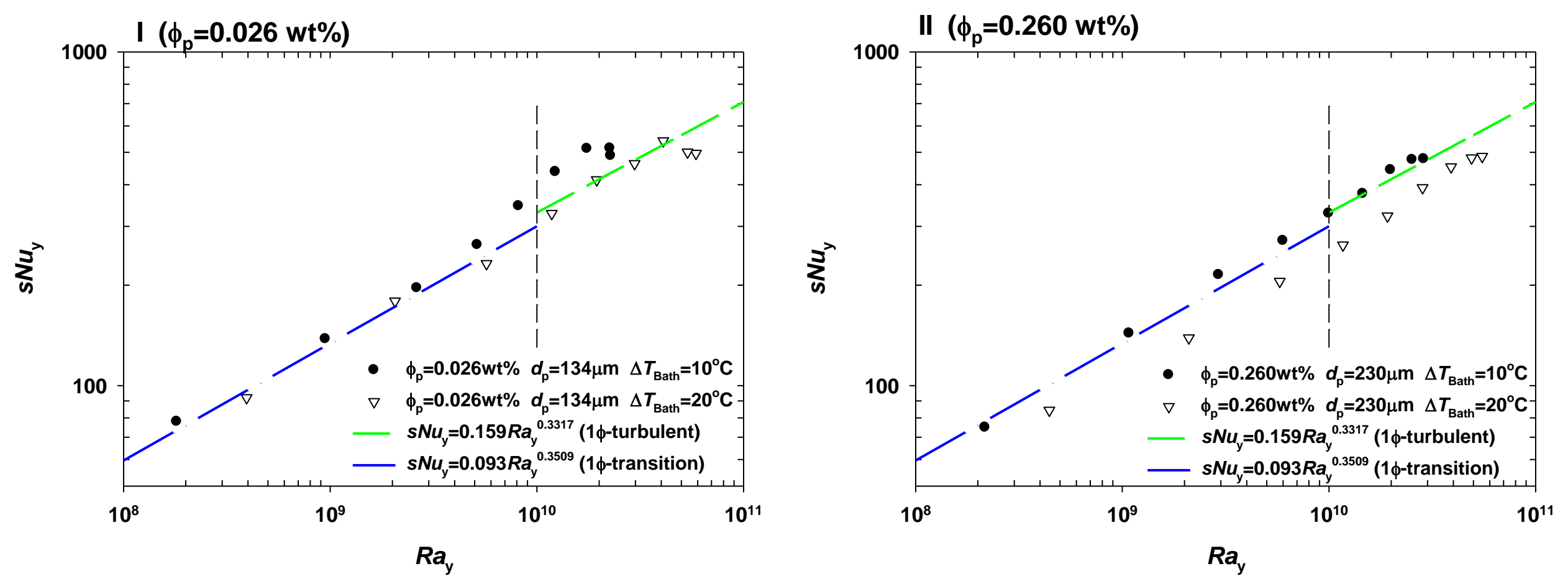

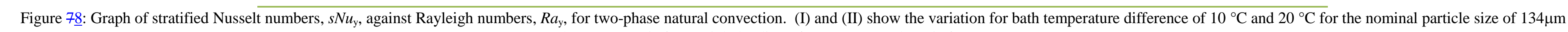
and $230 \mu \mathrm{m}$. (I) is for particle loading of $0.026 \mathrm{wt} \%$ and (II) is for $0.260 \mathrm{wt} \%$. 

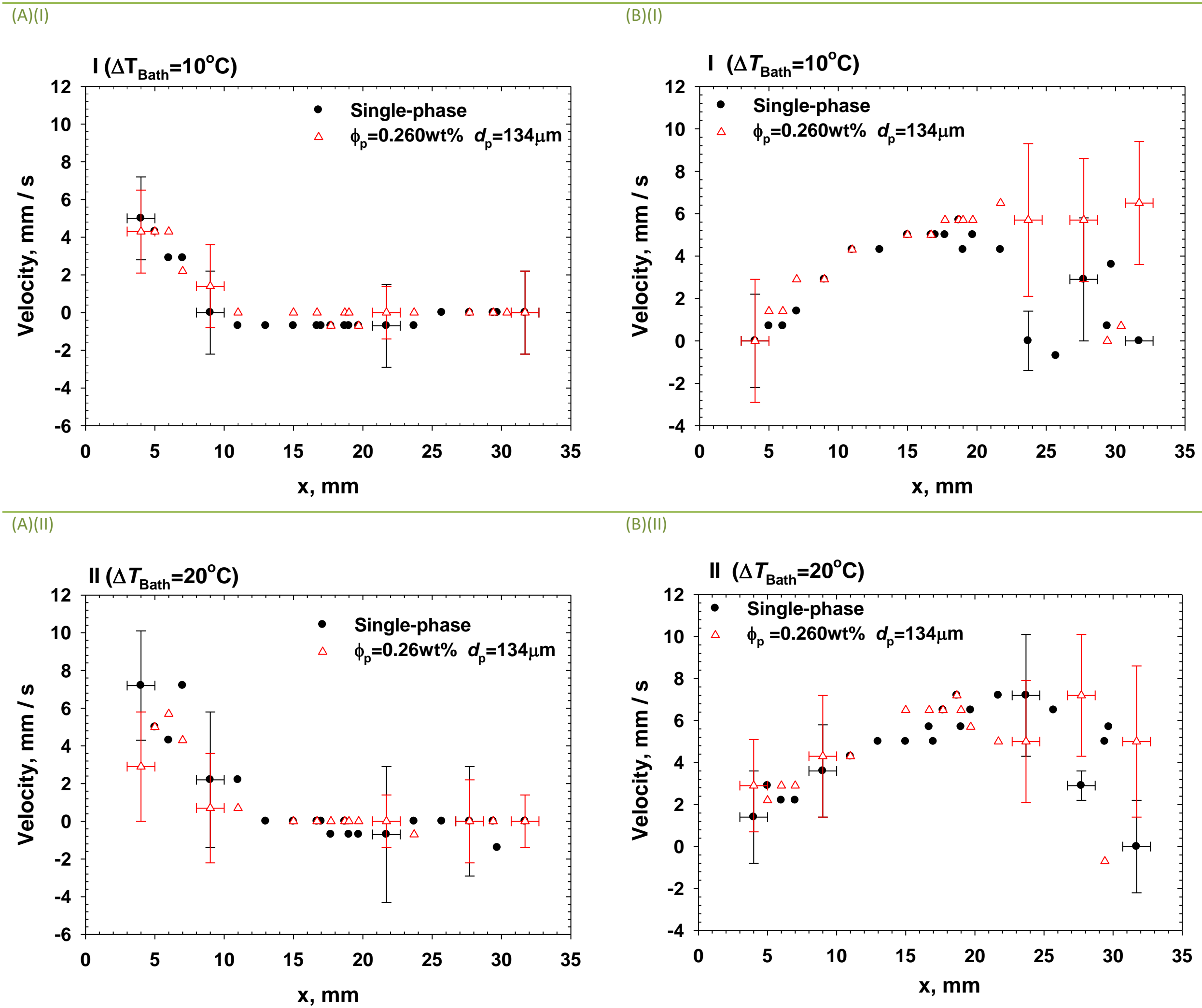

Figure 89: (A). Velocity profiles for single- and two-phase flows at $y / H=0.944$. For two-phase case, particle size is $134 \mu \mathrm{m}$ and particle loading is $0.26 \mathrm{wt} \%$. (A)(I) is for bath temperature difference of $10^{\circ} \mathrm{C}$ and (A)(II) is for $20^{\circ} \mathrm{C}$. (B). Velocity profiles for single- and two-phase flows at $y / H=0.538$. For two-phase case, particle size is $134 \mu \mathrm{m}$ and particle loading is 0.26 wt $\%$. (B)(I) is for bath temperature difference of $10^{\circ} \mathrm{C}$ and (B)(II) is for $20^{\circ} \mathrm{C}$. 


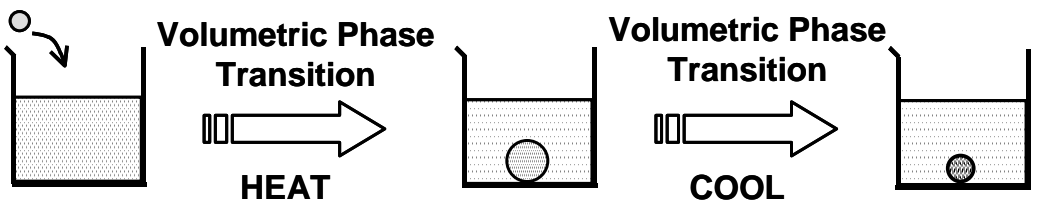
1) Dry state Target particles
1 in wasterwater
2) Swollen state T > LCST
3) Collapsed state (T < LCST)
Absorb, encapsulated solid particles

Fig. 910(A)

3

4

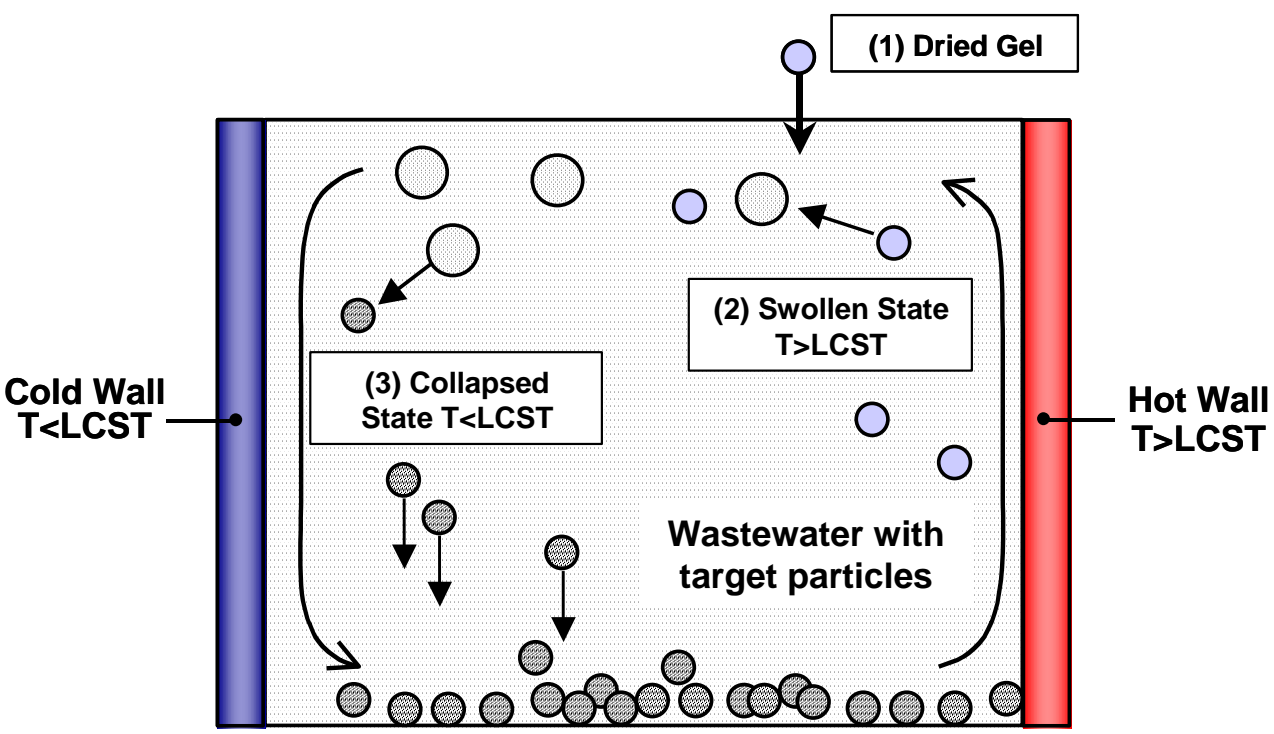

5

(4) Sedimentation $\rightarrow$ Separation

6 Fig. $9 \underline{10}(B)$

7

8 Figure 910: (A) Schematic of gelatin particle with volumetric phase transition and interaction with solid 9 particles. (B) Schematic of proposed Dynamic Filtering System (DFS). LCST denotes lower critical 10 suspension temperature. 


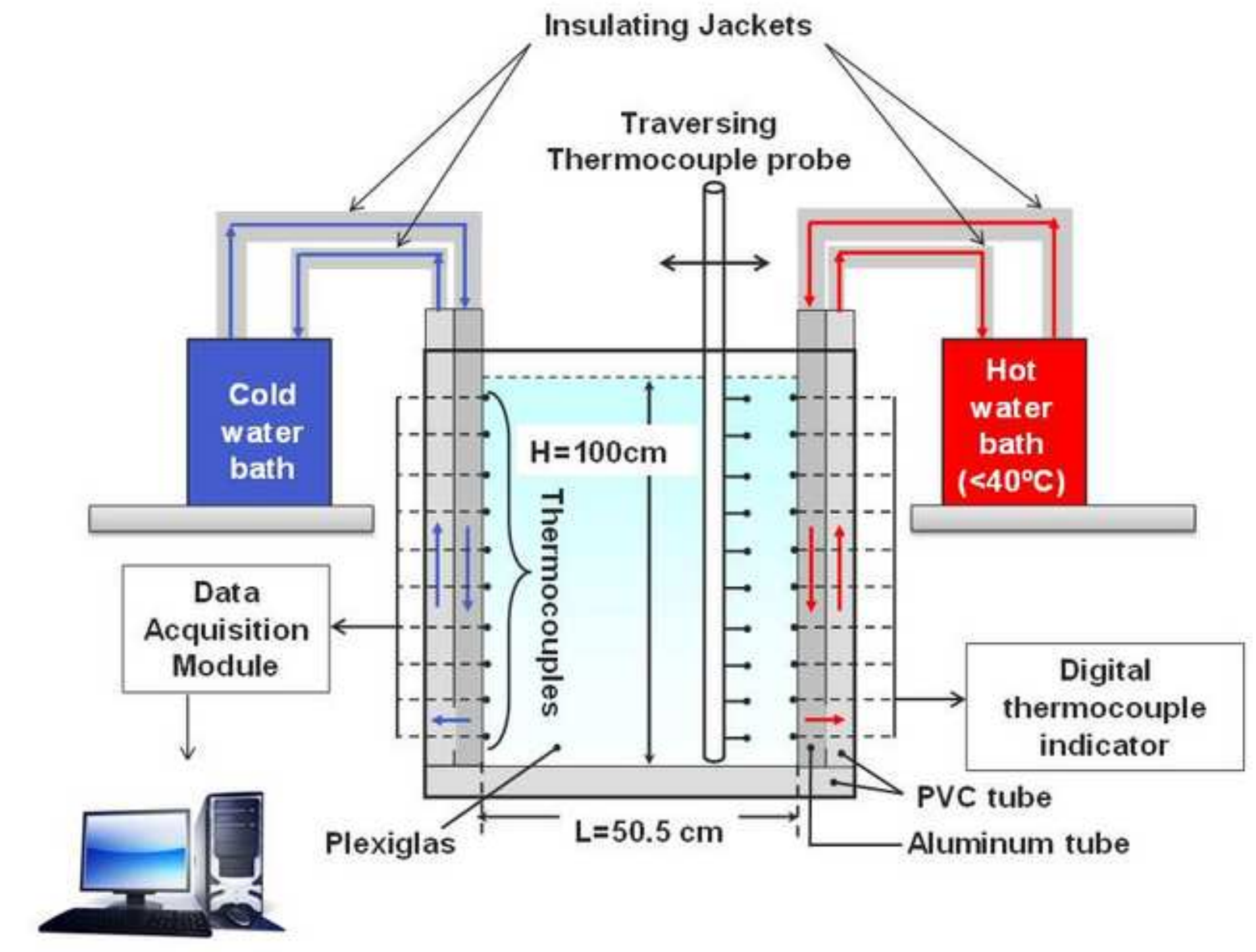

.




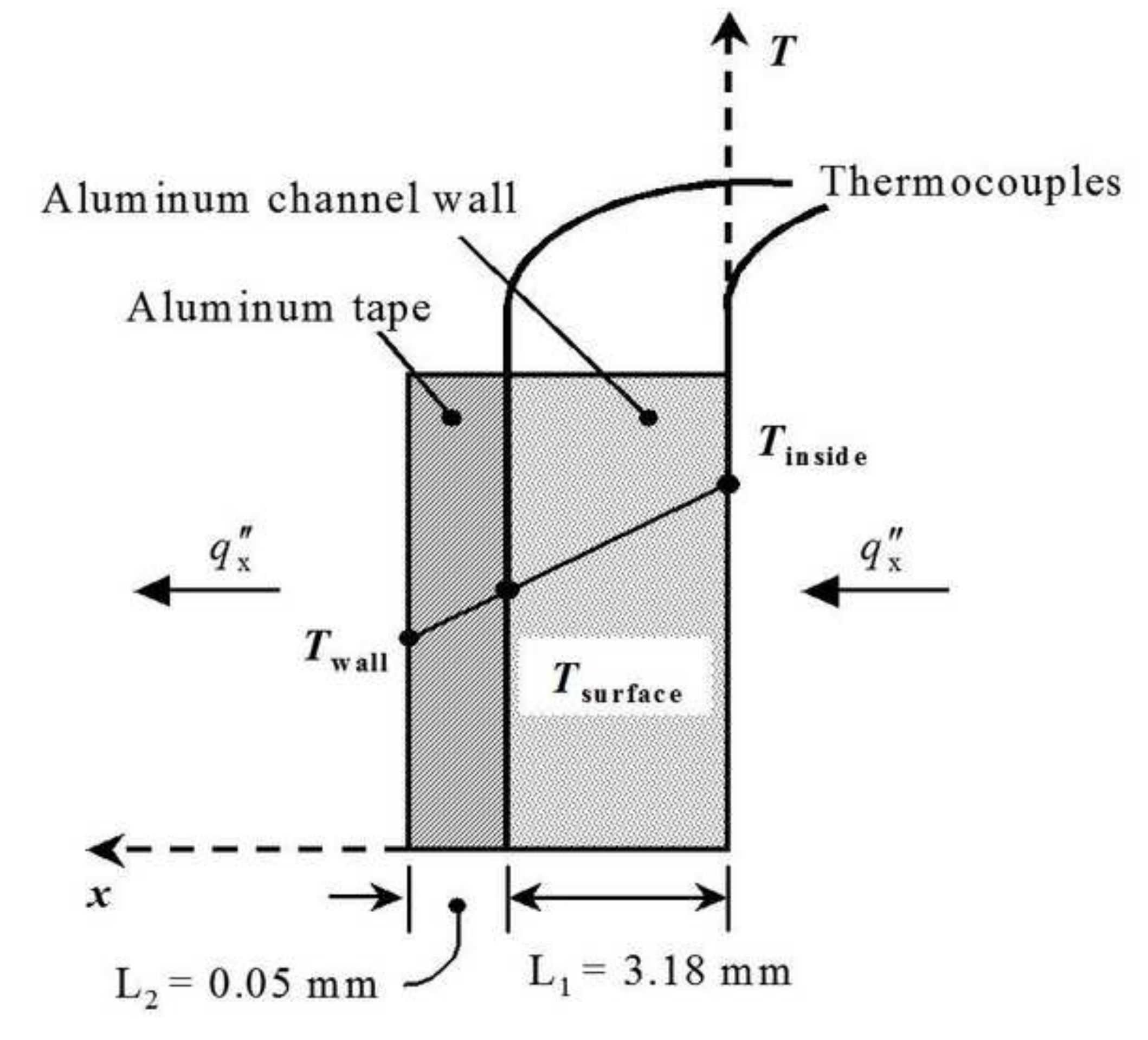




\section{US Transducers}

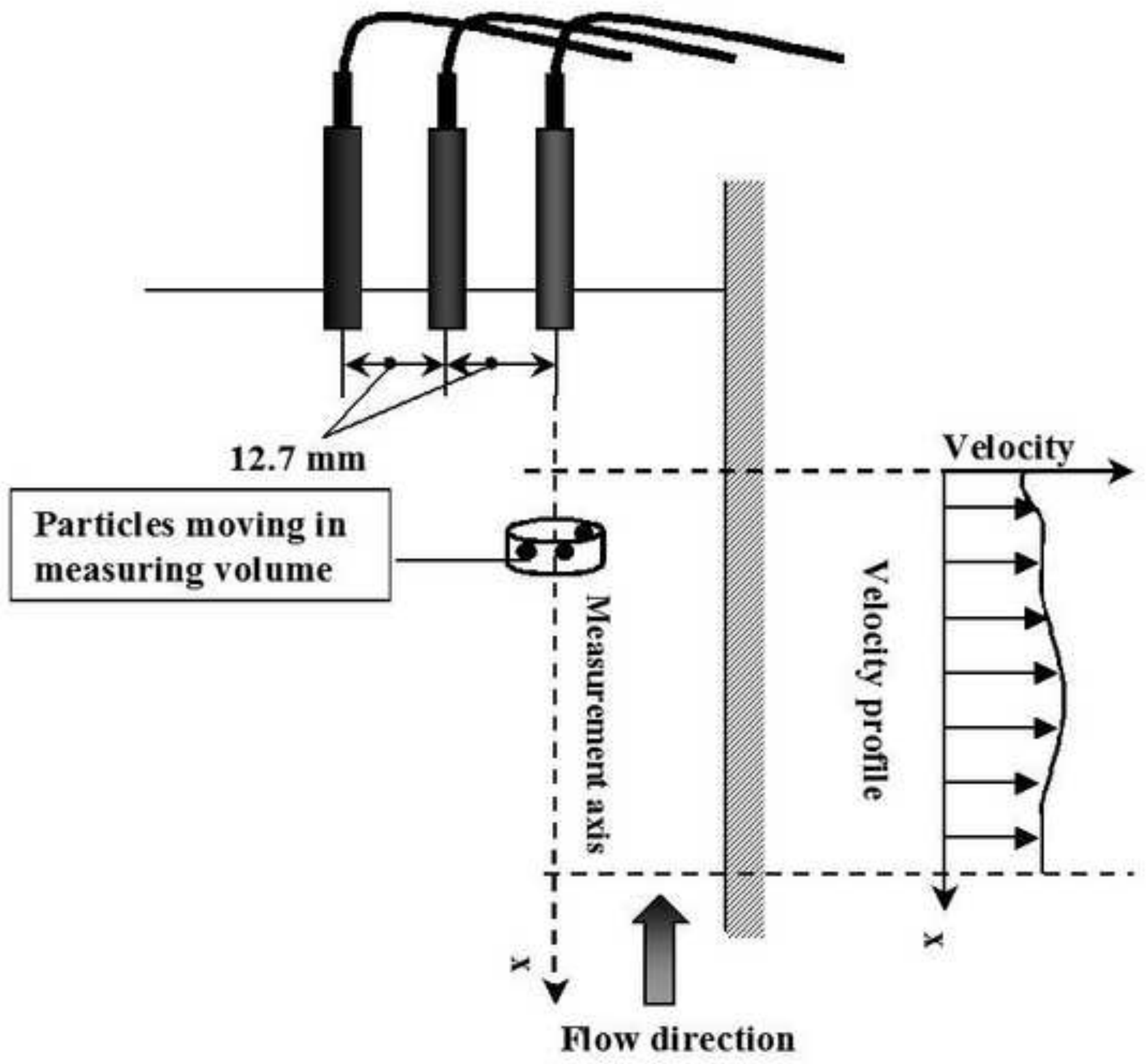

